\title{
Two Input Systems for Body Representations in the Primate Striatal Matrix: Experimental Evidence in the Squirrel Monkey
}

\author{
Alice W. Flaherty ${ }^{1,2}$ and Ann M. Graybiel ${ }^{1}$ \\ 'Department of Brain and Cognitive Sciences, Massachusetts Institute of Technology, Cambridge, Massachusetts 02139 \\ and ${ }^{2}$ Division of Health Sciences and Technology, Harvard Medical School, Boston, Massachusetts 02115
}

The striatum is important in basal ganglia motor control and movement disorders. In this study we demonstrate the existence of two distinct sensorimotor cortical input systems to the striatum of the squirrel monkey. The first is a group of discrete zones in the extrastriosomal matrix of the putamen ('matrisomes') that receive somatotopically organized projections from both the body map in ipsilateral primary motor cortex (MI) and maps in ipsilateral primary somatosensory cortex (SI). The second system is a group of matrisomes in largely different locations that receive somatotopically organized inputs from contralateral MI but not SI.

Intracortical microstimulation and multiunit recording were used to guide deposits of multiple anterograde tracers in MI and SI. Striosome/matrix architecture was demonstrated by enkephalin immunohistochemistry. We found that inputs from regions of ipsilateral $M I$ and SI that represented the same body parts sent projections to the same matrisomes of the ipsilateral putamen. Contralateral MI sent its strongest inputs to matrisomes that tended to interdigitate with those receiving inputs from ipsilateral SI and MI, except the contralateral MI face region, which sent projections that overlapped those from the ipsilateral MI face region. MI regions representing axial body parts (trunk and face) sent stronger representations to the contralateral putamen than did those representing distal parts (hand and foot). SI sent no contralateral projection. Thus, with the exception of the face representation, inputs from contralateral and ipsilateral body representations may alternate in the primate striatal matrix, an arrangement reminiscent of the alternating ocular dominance columns in visual cortex. Ipsilateral SI and $\mathrm{MI}$ and contralateral $\mathrm{MI}$ all innervated matrisomes intermingled with striosomes and with matrisomes not receiving sensorimotor cortical input. The patchiness of these maps is thus unlike the smoother somatotopic maps of sensorimotor cortex, and is also unlike the fractured somatotopy reported for the cerebellum.

[Key words: basal ganglia, striatum, neostriatum, putamen, sensorimotor cortical input systems, motor cortex, somatosensory cortex]

\footnotetext{
Received July 1, 1992; revised Sept. 16, 1992; accepted Sept. 22, 1992.

We thank H. F. Hall for help with the photography. This work was supported by Javits Award NIH R0125529 and the Human Frontier Science Program.

Correspondence should be addressed to Ann M. Graybiel, E25-618, M.I.T., Cambridge, MA 02139.

Copyright (C) 1993 Society for Neuroscience $0270-6474 / 93 / 131120-18 \$ 05.00 / 0$
}

To understand the differences between the way the cerebral cortex and basal ganglia control movement, it has been useful to compare their motor and somatosensory representations of the body (see, e.g., Crutcher and Alexander, 1990; Mink and Thach, 1991). In this study we focused on the map transformations that occur when information about the body is sent from the cortex to the striatum. Electrophysiological and anatomical experiments have shown that the representation of the contralateral body in the primate putamen is unlike its representations in primary somatosensory cortex (SI) and primary motor cortex (MI) in being distinctly patchy. Electrically excitable zones and input zones for corticostriatal projections are surrounded by tissue thought to be without strong sensorimotor input (Künzle, 1975, 1978; Crutcher and DeLong, 1984; Alexander and DeLong, 1985b; Liles and Updyke, 1985). There has been continuing debate about the extent to which inputs from different areas of cerebral cortex are integrated at successive stages within the basal ganglia (see, e.g., Percheron and Filion, 19y0), but there is now evidence for anatomical convergence in the putamen of somatotopically related inputs from arcas $3 \mathrm{a}, 3 \mathrm{~b}$, and $1-$ SI cortical areas with different somatosensory submodalities (Flaherty and Graybiel, 1991a).

It is not obvious a priori whether MI projections also converge with SI projections, because, aside from their grossly equivalent somatotopy, body representations in MI and SI could be fundamentally different in their organization and in their influence on motor control by the basal ganglia. There has been one preliminary report of the relation between ipsilateral MI and SI projections to the primate striatum (Fotuhi et al., 1989), but the body part representations of the cortical areas studied were not electrophysiologically identified. The degree to which MI and SI inputs to the putamen are somatotopically related, the relative contributions of different body part representations, and the role of the contralateral projection have not been previously studied.

Within the striatum, the extrastriosomal matrix is of particular importance to motor control by the basal ganglia: it is a target of MI and SI inputs, and it projects to other nuclei with movement-related activity: the globus pallidus and substantia nigra pars reticulata. Recent work has demonstrated that in squirrel monkeys SI projects to sets of distributed zones in the matrix (Flaherty and Graybiel, 1991a), but it is not known whether in primates MI inputs are contained entirely in the matrix (Koliatsos et al., 1988), or, if so, whether they fill the matrix homogeneously or interact with other, interdigitating matrix systems. In light of evidence that corticostriatal projections in the rat may be organized by cortical layer rather than by cortical area (Gerfen, 1989), it was important to confirm that the primate $\mathrm{MI}$ projects primarily to the matrix. 
In general, in cats and primates the matrix is not homogeneous tissue surrounding striosomes. Rather, the inputs and outputs of the matrix are organized in zones roughly the same size as striosomes. We have called these matrix modules "matrisomes" (Graybiel et al., 1991), in order to avoid the awkward phrase "patches in the matrix." It is not yet clear whether such matrisomes, defined by their connections, are like striosomes in being fixed tissue compartments that can be picked out by multiple criteria, or whether matrisomes defined by different inputs and outputs have shifting relations to one other. We thus were particularly interested in whether inputs from MI and SI converge on the same or different sets of matrisomes.

In the experiments described here, we combined electrophysiological stimulation and recording with injections of multiple tract tracers and with immunohistochemistry to determine the relationship between striatal architecture and projections from ipsilateral and contralateral body part representations. Tracer injections were made in either MI or SI. Although SI itself comprises four areas with different receptive field physiology, cytoarchitecture, and connections, we did not try to confine SI injection sites to single areas because our previous work showed that, despite their differences, these SI areas send very similar, overlapping projections to the putamen (Flaherty and Graybiel, 1991a).

Our observations have been briefly summarized elsewhere (Flaherty and Graybiel, 1991b).

\section{Materials and Methods}

In 11 adult squirrel monkeys (Saimiri sciureus), bilateral electrophysiological maps of MI and SI were made to guide the placement of the anterograde tracers ${ }^{35} \mathrm{~S}$-methionine and wheat germ agglutinin-conjugated horseradish peroxidase (WGA-HRP) into selected sites within MI and SI. The distributions of the tracers transported to the striatum were compared to each other, and to striosomes demonstrated by enkephalinlike immunoreactivity, in serial sections. Table 1 summarizes the protocols for the 11 monkeys. In the course of the experiments, distinguishable retrograde tracers were also deposited elsewhere in the brains for experiments to be reported separately.

Surgerics and histology were performed as described previously (Flaherty and Graybiel, 1991 a). Briefly, monkeys were given a small dose of the analgesic buprenorphine $\mathrm{HCl}(0.01 \mathrm{mg} / \mathrm{kg}$, s.c. $)$ preoperatively, and then anesthetized with ketamine $(30 \mathrm{mg} / \mathrm{kg}, \mathrm{i} . \mathrm{m}$.) and a single initial dose of sodium pentobarbital $(5 \mathrm{mg} / \mathrm{kg}$, i.p.). A few monkeys did not receive buprenorphine, instead receiving a larger dose of sodium pentobarbital $(10 \mathrm{mg} / \mathrm{kg}$, i.p.). Anesthetic level was determined by monitoring heart rate with an ECG, respiration rate, muscle tone, and toepinch and blink reflexes. Supplementary doses of ketamine $(10 \mathrm{mg} / \mathrm{kg}$, i.m.) were given as needed to maintain anesthesia. Large bone and dural flaps were turned with sterile technique, the cortical surface was covered with high-viscosity silicon oil, and microelectrode penetrations were made at $500-1000 \mu \mathrm{m}$ intervals to determine the boundaries of body part representations in cortical areas $4,3 a, 3 b$, and 1 . Electrode penetrations were made at depths that maximized the stimulated or recorded response, typically $0.8-1.4 \mathrm{~mm}$. The location of each cortical electrode penetration was marked on an enlarged photograph of the exposed cortex, and the stereotactic coordinate of each penetration was noted.

Multiunit neuronal activity was recorded with parylene-coated tungsten electrodes (Microprobe) with impedances of $0.8 \mathrm{M} \Omega \pm 15 \%$ at 1 $\mathrm{kHz}$. The borders of areas $3 \mathrm{a}, 3 \mathrm{~b}$, and 1 were determined as described previously (Flaherty and Graybiel, 1991a). Receptive fields were identified as cutaneous or noncutaneous by stimulating the skin with fine hand-held probes. Cutaneous fields were defined as regions from which a vigorous neural response could be elicited with very gentle tactile stimulation of the skin. Noncutaneous fields were defined as those unresponsive to light touch but sensitive to forceful taps or to manipulation of underlying tissues or joints.

MI was defined according to the criteria of Sessle and Wiesendanger (1982). Both intracortical electrical stimulation and cytoarchitectonic boundaries were examined. Trains of symmetric biphasic paired pulses, $0.3 \mathrm{msec}$ each, were delivered at $300 \mathrm{pulse}-\mathrm{pairs} / \mathrm{sec}$. Stimuli were delivered from an optically coupled stimulus isolator (Bak BSI-2) driven by a biphasic pulse generator (Bak RP-1), through platinum-iridium microelectrodes (Microprobe) with impedances of $1.0 \mathrm{M} \Omega \pm 5 \%$ at 1 $\mathrm{kHz}$. Current amplitude and pulse waveform were monitored intermittently on an oscilloscope by recording differentially across a $1 \mathrm{k} \Omega$ resistor in series with the microelectrode. Motor responses to microstimulation were considered to be present when either visible movement about a joint or visible muscle contraction occurred in a reproducible manner at a constant stimulus. If movement was detected at $100 \mu \mathrm{A}$ the current was gradually lowered until the threshold value was reached. As little as $3 \mu \mathrm{A}$ was sufficient to stimulate movement in monkeys that received small initial doses of sodium pentobarbital. In the few monkeys that received larger doses of sodium pentobarbital, thresholds of $20-40$ $\mu \mathrm{A}$ were more common. If no movement was detected, currents up to $400 \mu \Lambda$ were tried briefly. The area 4 movement maps generated were similar in overall organization to previous, more detailed maps (Kwan et al., 1978; Sessle and Wiesendanger, 1982; Gould et al., 1986; Donoghue el al., 1992).

At the end of the mapping session, ${ }^{35} S$-methionine $(200 \mu \mathrm{Ci} / \mu \mathrm{l}$ in sterile saline) and WGA-HRP (15\% in sterile saline) were placed at physiologically characterized sites in Sl and $\mathrm{MI}$ by reference to the photographic records made during the mapping session. Tracer deposits in SI were centered in area 3b. Two types of injections were made: small deposits designed to be within a given body part representation of a single cortical area (monkeys 32, 37, and 40-42), and large injections intended to completely fill, but not exceed, most or all of the body part representations in a given area (monkeys 33-35). Postoperatively, animals were maintained on the analgesics butorphanol tartrate $(0.025$ $\mathrm{mg} / \mathrm{kg}$, s.c., t.i.d. $)$ or buprenorphine $\mathrm{HCl}(0.01 \mathrm{mg} / \mathrm{kg}$, s.c., b.i.d.). Two to three days after surgery, animals were perfused through the heart with $0.9 \%$ saline, then $4 \%$ paraformaldehyde in a $0.1 \mathrm{M}$ phosphatebuffered $5 \%$ sucrose solution, and finally a postwash with phosphatebuffered sucrose. Brains were blocked in a stereotaxic device, and blocks were soaked $1-3 \mathrm{~d}$ in $20 \%$ glycerol, frozen, and cut coronally in $40 \mu \mathrm{m}$ sections on a sliding microtome. Adjacent sections were processed in series to compare the distributions of injected tracers and enkephalin immunoreactivity

To demonstrate ${ }^{35} \mathrm{~S}$-methionine, slide-mounted sections were dipped in diluted Kodak NTB-2 emulsion, stored in the dark at $-20^{\circ} \mathrm{C}$ for 7 d to 7 months, developed in Kodak D-19, counterstained with cresylecht violet, and coverslipped. WGA-HRP reaction product was demonstrated by the tetramethyl benzidine (TMB) procedure of Mesulam (1978) except that the incubation solution was changed every $3 \mathrm{~min}$ to prevent precipitation (Illing and Graybiel, 1986). For enkephalin immunohistochemistry, sections were incubated for $2 \mathrm{~d}$ in anti-met-enkephalin (Incstar; 1:2000 dilution), and bound antibody was labeled with the avidin-biotin-peroxidase technique. Striosomes were identified as zones of low met-enkephalin-like immunoreactivity (Graybiel and Chesselet, 1984).

Sections were studied under bright- and dark-field illumination, and those stained with TMB were placed between crossed polarizers (Illing and Wässle, 1979). The distributions of tracers in the striatum were charted at magnifications between $10 \times$ and $40 \times$ with a drawing tube or with a Biocom image analyzer. Corticostriatal labeling was classified in two categories, "hot spots" of dense labeling and surrounding zones of weaker labeling. These categories were generally assigned by eye, but were occasionally checked by computerized optical density threshold analysis. Adjacent sections were aligned with reference to local blood vessels. Injection sites charted in the coronal sections were reconstructed on the cortical surface with respect to the in vivo electrophysiological map by reference to the tracks of the injection pipettes, electrode penetrations, stereotaxic coordinates, and sulcal patterns, as previously described (Flaherty and Graybiel, 1991a), taking into account the greater shrinkage of the TMB-stained sections. All injection sites described in this article extended through all cortical layers. Because injections that did not penetrate to cortical layer $V$ did not produce analyzable amounts of label in the striatum, injection site widths were measured at the level of layer $V$, rather than at the surface of the cortex (Flaherty and Graybiel, 1990). The locations of all the tracer deposits were also mapped with respect to the distribution of the giant pyramidal Betz cells of area 4 . Anteroposterior (A-P) levels of sections were assigned according to the atlas of Gergen and MacLean (1962). 


\begin{tabular}{|c|c|c|c|c|c|}
\hline $\begin{array}{l}\text { Experi- } \\
\text { ment }\end{array}$ & Hemisphere & Tracer & $\begin{array}{l}\text { Injected } \\
\text { area }\end{array}$ & $\begin{array}{l}\text { Injected } \\
\text { representation }\end{array}$ & Figures \\
\hline 29 & $\mathbf{R}$ & $\begin{array}{l}\text { Met } \\
\text { HRP } \\
\text { HRP }\end{array}$ & $\begin{array}{l}\text { SI } \\
\text { MI } \\
\text { SI }\end{array}$ & $\begin{array}{l}\text { All but head } \\
\text { Foot } \\
\text { Foot }\end{array}$ & $1 D-F$ \\
\hline 30 & $\mathbf{R}$ & $\begin{array}{l}\text { Met } \\
\text { HRP } \\
\text { Met } \\
\text { HRP }\end{array}$ & $\begin{array}{l}\text { SI } \\
\text { SI } \\
\text { SI } \\
\text { SI }\end{array}$ & $\begin{array}{l}\text { Hand } \\
\text { Foot } \\
\text { Foot } \\
\text { Hand }\end{array}$ & $3 B, B^{\prime}$ \\
\hline 32 & $\begin{array}{l}\mathbf{L} \\
\mathbf{R}\end{array}$ & $\begin{array}{l}\text { Met } \\
\text { HRP } \\
\text { Met } \\
\text { HRP }\end{array}$ & $\begin{array}{l}\text { MI } \\
\text { SI } \\
\text { MI } \\
\text { SI }\end{array}$ & $\begin{array}{l}\text { Foot } \\
\text { Foot } \\
\text { Foot } \\
\text { Foot }\end{array}$ & $2 A-D$ \\
\hline 33 & $\begin{array}{l}\mathbf{L} \\
\mathbf{R}\end{array}$ & $\begin{array}{l}\text { Met } \\
\text { Met } \\
\text { HRP }\end{array}$ & $\begin{array}{l}\text { SI } \\
\text { SI } \\
\text { MI }\end{array}$ & $\begin{array}{l}\text { All but head } \\
\text { All but head } \\
\text { Foot and leg }\end{array}$ & $4 A-C$ \\
\hline 34 & $\begin{array}{l}\mathrm{L} \\
\mathrm{R}\end{array}$ & $\begin{array}{l}\text { HRP } \\
\text { HRP } \\
\text { Met }\end{array}$ & $\begin{array}{l}\text { SI } \\
\text { SI } \\
\text { MI }\end{array}$ & $\begin{array}{l}\text { All but head } \\
\text { All but head } \\
\text { Foot and leg }\end{array}$ & \\
\hline 35 & $\begin{array}{l}\mathrm{L} \\
\mathrm{R}\end{array}$ & $\begin{array}{l}\text { HRP } \\
\text { Met }\end{array}$ & $\begin{array}{l}\text { MI } \\
\text { MI }\end{array}$ & $\begin{array}{l}\text { All but head } \\
\text { All but head }\end{array}$ & $\begin{array}{l}1 A, B ; 5 A, B \\
1 A, C ; 5 A, 8,9\end{array}$ \\
\hline 36 & $\begin{array}{l}\mathrm{L} \\
\mathrm{R}\end{array}$ & $\begin{array}{l}\text { HRP } \\
\text { Met } \\
\text { Met }\end{array}$ & $\begin{array}{l}\text { MI } \\
\text { SI } \\
\text { SI }\end{array}$ & $\begin{array}{l}\text { Foot } \\
\text { Trunk } \\
\text { Trunk }\end{array}$ & \\
\hline 37 & $\begin{array}{l}\mathrm{L} \\
\mathrm{R}\end{array}$ & $\begin{array}{l}\text { HRP } \\
\text { Met } \\
\text { Met }\end{array}$ & $\begin{array}{l}\text { MI } \\
\text { SI } \\
\text { SI }\end{array}$ & $\begin{array}{l}\text { Foot } \\
\text { Trunk } \\
\text { Trunk }\end{array}$ & $3 A, A^{\prime}$ \\
\hline 40 & $\begin{array}{l}\mathrm{L} \\
\mathbf{R}\end{array}$ & $\begin{array}{l}\text { HRP } \\
\text { Met } \\
\text { Met } \\
\text { HRP }\end{array}$ & $\begin{array}{l}\text { MI } \\
\text { MI } \\
\text { MI } \\
\text { MI }\end{array}$ & $\begin{array}{l}\text { Foot } \\
\text { Mouth } \\
\text { Foot } \\
\text { Mouth }\end{array}$ & $\begin{array}{l}6.4, A^{\prime} \\
6 B, B^{\prime}\end{array}$ \\
\hline 41 & $\begin{array}{l}\mathrm{L} \\
\mathrm{R}\end{array}$ & $\begin{array}{l}\text { HRP } \\
\text { Met }\end{array}$ & $\begin{array}{l}\text { MI } \\
\text { MI }\end{array}$ & $\begin{array}{l}\text { Trunk } \\
\text { Trunk }\end{array}$ & $7 A, A^{\prime}$ \\
\hline 42 & $\begin{array}{l}\mathrm{L} \\
\mathrm{R}\end{array}$ & $\begin{array}{l}\text { HRP } \\
\text { Met }\end{array}$ & $\begin{array}{l}\text { MI } \\
\text { MI }\end{array}$ & $\begin{array}{l}\text { Hland } \\
\text { Hand }\end{array}$ & $7 B, B^{\prime}$ \\
\hline
\end{tabular}

\section{Results}

Motor and somatosensory cortex each send modular inputs to the putamen

Bilateral inputs from $M I$ to the striatum. When large tracer deposits were made along much of the length of MI (four hemispheres), anterograde labeling in the ipsilateral putamen filled multiple clusters and bands that appeared as discrete patches in cross section. At the densest part of its A-P extent (about A 10.0 to $\mathrm{A} 12.0$ ), the corticostriatal projection formed a nearly confluent "main field" of label with faint satellite zones around it (Fig. 1C). But even the largest of the tracer deposits in MI produced multiple discrete zones of labeling at more anterior and posterior levels of the putamen (see, e.g., Figs. $5 B, 8 A$ ). Occasionally the lateral edge of the rostral caudate nucleus contained weak labeling as well.

When small tracer deposits were placed in restricted regions of MI (11 hemispheres), the clusters and bands were smaller and more discrete than those labeled by large cortical injections (Fig. $2 B$ ). The bands were similar in shape and location to the previously described pattern of ipsilateral labeling following small tracer deposits in somatosensory cortex (Flaherty and Graybiel, 1991a), but when MI and SI injection sites were the same size, the MI projections tended to be larger and more densely labeled. The distributions of labeled projections in the ipsilateral putamen showed the expected rough somatotopy - projections from the foot region tended to be most dorsal, and head most ventral.

Labeled projections from MI to the contralateral putamen appeared at approximately the same A-P levels as they did in the ipsilateral putamen, and they had a similar somatotopic organization. Contralateral inputs also resembled ipsilateral inputs in being broken into distinct zones. These were, however, smaller and fainter than those on the ipsilateral side, and their distribution was roughly the inverse of those on the ipsilateral side. For instance, the lateral edge of the putamen was often 
A

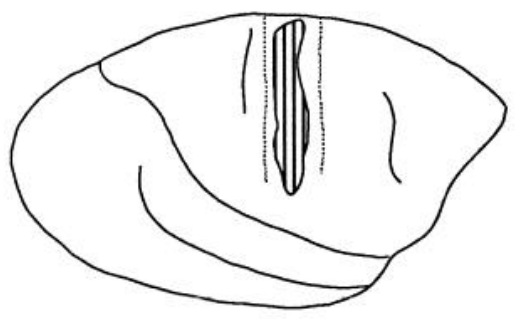

MI injection site

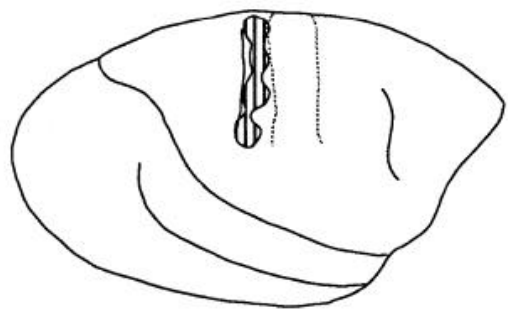

SI injection site

D
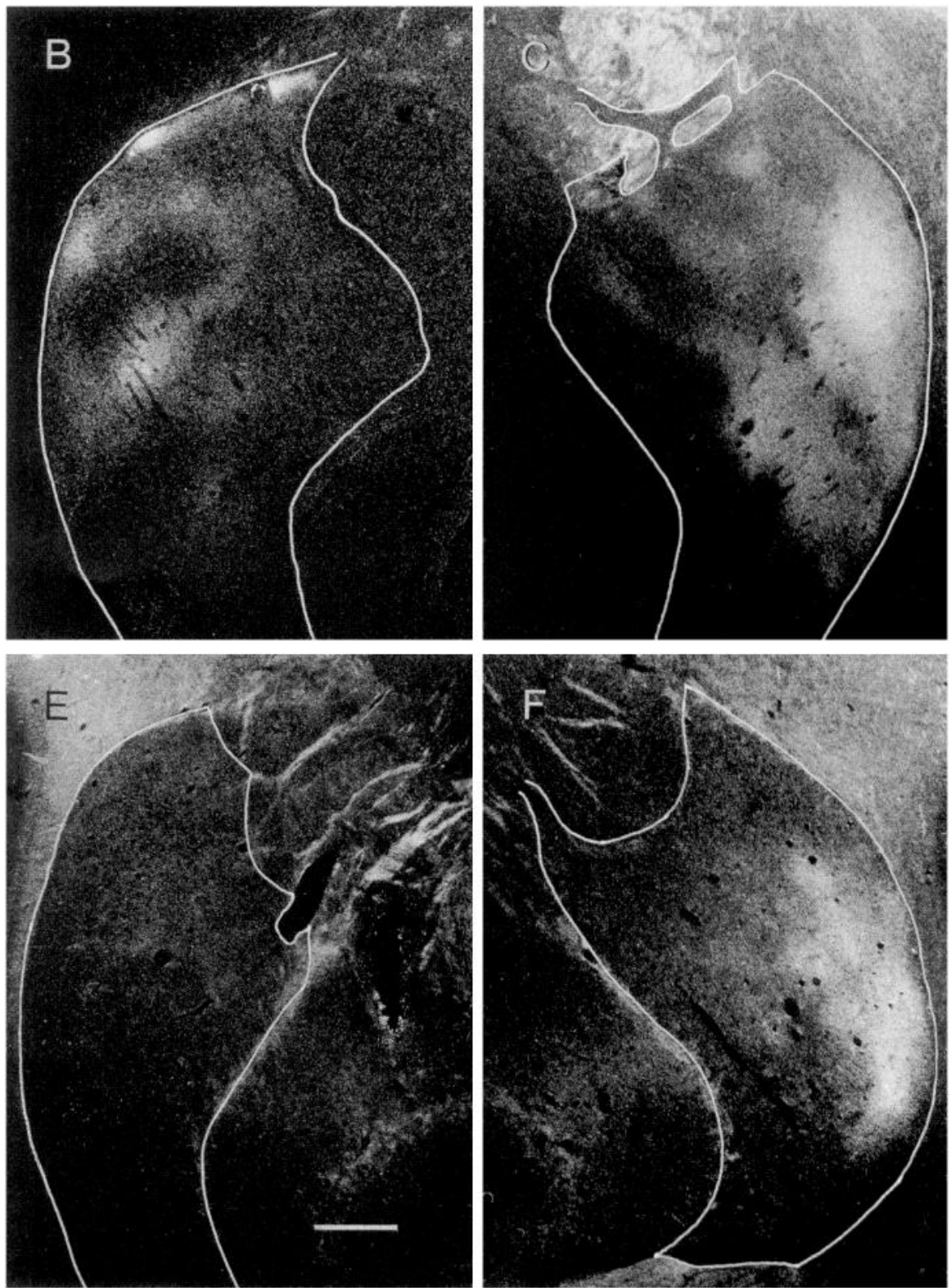

Figure 1. MI projects bilaterally to the putamen $(A-C$; monkey 35$)$, but SI projects ipsilaterally ( $D-F$; monkey 29$)$. $A$ and $D$, Reconstructions of the ${ }^{35} \mathrm{~S}$-methionine tracer injection sites. Broken lines indicate the boundaries of Betz cell distribution. Figure $5 A$ shows a more detailed view of $A$. $B$ and $C$, Dark-field photomicrographs of a coronal section through the putamen of monkey 35 at $\mathrm{A} 11.5$, showing labeled ipsilateral $(C)$ and contralateral $(B)$ corticostriatal projections. $E$ and $F$, Dark-field photomicrographs of a coronal section through the putamen of monkey 29 at $\mathrm{A}$ 10.5 , showing the ipsilateral SI corticostriatal projection $(F)$ and the absence of contralateral SI projection $(E)$. Borders of the putamen are outlined. $D-F$ are printed backward for ease of comparison with $A-C$. Scale bar, $1 \mathrm{~mm}$.

studded with discrete patches of label on the contralateral but not on the ipsilateral side, and the zone in the central putamen that received the confluent main field of the ipsilateral projection was often free of label contralaterally (Fig. 1B).

Ipsilateral inputs from SI to the striatum. To compare the projections from SI to the striatum with those from ipsilateral and contralateral MI, it was necessary to confirm in the squirrel monkey, for all of area $3 \mathrm{~b}$ and adjacent SI areas, previous reports that there is no cross-projection to the primate striatum from SI cortex (Jones et al., 1977; Flaherty and Graybiel, 1991a). We therefore made an extensive tracer deposit in SI, depositing a total of $120 \mathrm{nl}$ of ${ }^{35} \mathrm{~S}$-methionine in 11 spaced injections along area $3 \mathrm{~b}$, and labeling somatosensory cortex from the foot through the hand representations (Fig. 1D). The labeling produced in the ipsilateral putamen by this injection was intense (Fig. $1 F$ ). The contralateral putamen is shown in Figure $1 E$. Even after a 7 month exposure of the autoradiographic slides, no transport to the contralateral putamen was visible in the foot, leg, trunk, arm, or hand regions of the putamen. By contrast, small $(10 \mathrm{nl})$ injections of ${ }^{35} \mathrm{~S}$-methionine into MI produced faint labeling in the contralateral striatum after an exposure time of about $10 \mathrm{~d}$.

\section{Somatotopically related inputs from SI and ipsilateral MI} predominantly converge in the putamen

To determine whether SI and MI project to the same zones in the ipsilateral putamen, we made both small and very large 


\section{A. Injection sites}
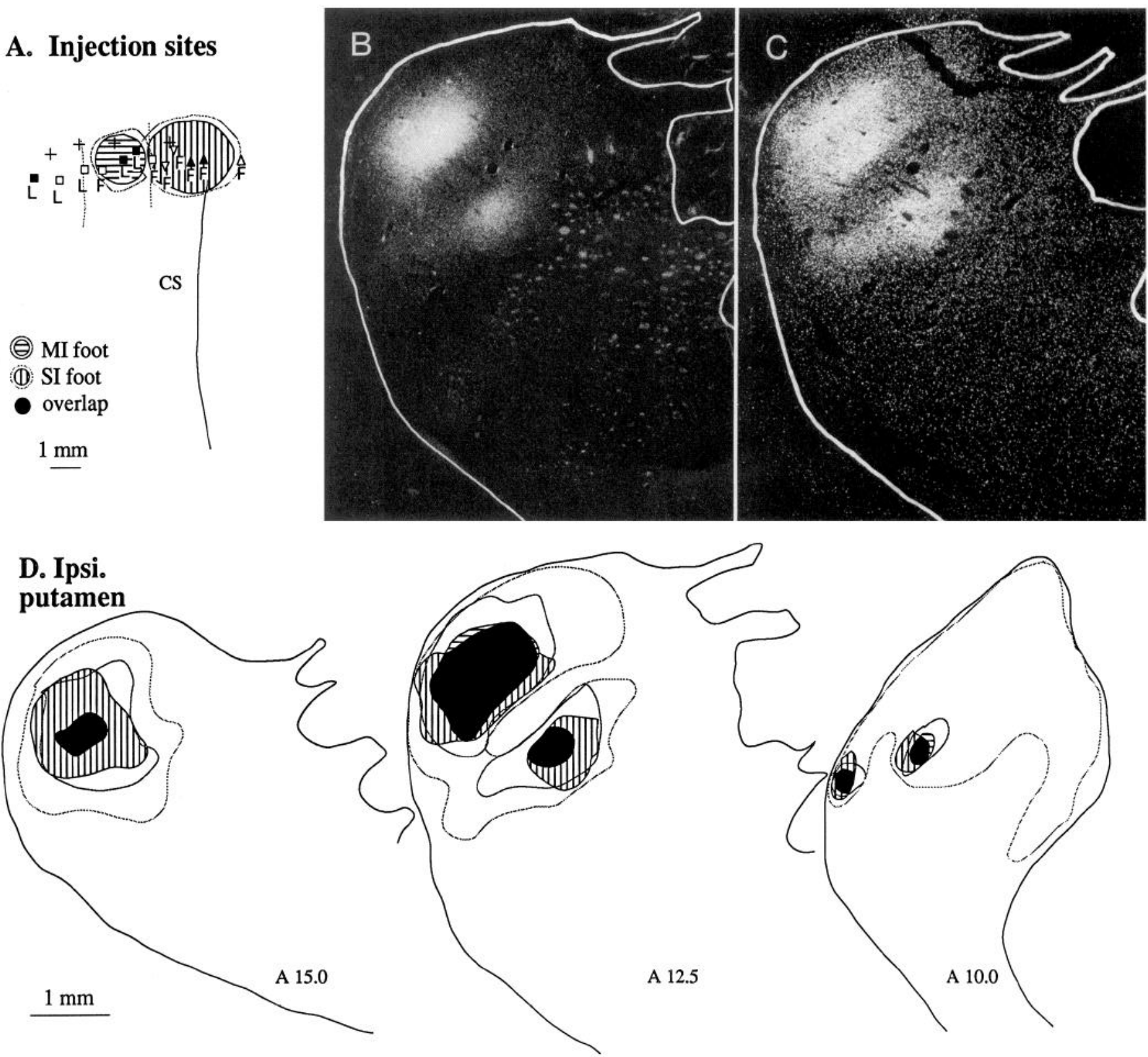

Figure 2. Regions representing matched body parts in MI and SI project mainly to overlapping regions of the putamen (monkey $32 \mathrm{~L}$ ). A, Reconstructions of tracer injection sites in the MI and SI foot areas, superimposed on the stimulation and recording maps. Hatched regions are areas in which the tracer penetrated to cortical layer V. Broken lines are boundaries of Betz cell distribution. Stimulating and recording electrode penetration sites are marked by symbols: $\nabla$, area $3 \mathrm{a} ; \boldsymbol{\Delta}$, area $3 \mathrm{~b} ; \Delta$, area $1 ;+$, no recorded response; $\boldsymbol{\square}$, movement stimulated $<100 \mu \mathrm{A} ; \square$, movement stimulated $\geq 100 \mu \mathrm{A} ; \times$, no stimulated response at $400 \mu \mathrm{A}$. CS, central sulcus. Other letters indicate sites of stimulated movement: $F$, foot; $L$, leg. $B$ and $C$, Dark-field photomicrographs of serial coronal sections through the putamen at A 12.5 , showing ${ }^{35}$ S-methionine-labeled inputs from the MI foot region $(B)$ and WGA-HRP-labeled inputs from the SI foot region $(C)$. Borders of the putamen are outlined. The two micrographs are also shown as an overlay charting in the middle of $D$. $D$, Overlay chartings of serial coronal sections through the putamen at three A-P levels, showing the overlap (black regions) of the densest zones of the MI input zones (horizontal hatches) and SI input zones (vertical hatches). Because in this monkey the MI injection site is smaller than the SI injection site, the MI input zones are smaller than the SI input zones, and are almost entirely within the SI zones in this monkey. Thus, most of the horizontal hatches indicating MI hot spots are covered with black regions. Atlas coordinates are given below sections.

paired injections in the two cortical areas, at pairs of sites representing either the same or different body parts.

In both hemispheres of monkey 32 (32L and 32R), we made small deposits of ${ }^{35} \mathrm{~S}$-methionine and WGA-HRP at, respectively, the foot representations of area 4 and area $3 \mathrm{~b}$. The injection sites for $32 \mathrm{~L}$ are shown in Figure $2 A$. The deposits in area $3 \mathrm{~b}$ extended into adjacent parts of area $3 \mathrm{a}$, but there was little or no overlap with the injection site centered in area 4 . In both hemispheres, the zones in the putamen that were densely labeled by the two tracers overlapped extensively, and the shapes, orientation, and numbers of the projection zones were similar (Fig. 2B-D). The correspondence held for both the zones of dense labeling and for the surrounding haloes of diffuse labeling.

There was some danger that the ipsilateral projections from MI to the striatum in monkey 32 were augmented by faint contralateral MI projections. To minimize this possibility, we 
first analyzed slides in which the autoradiographic emulsion had been exposed for only $10 \mathrm{~d}$, an exposure time that produced only faint contralateral labeling in other monkeys with foot region injection sites. Second, as we will describe below, the contralateral projection is largely noncongruent with the ipsilateral projection, and, if present, would only have obscured the correspondence seen here, rather than artifactually creating it. Third, in other monkeys ( 33 and 34 , discussed below) there was no possibility of cross-projection contamination, and yet the overlap between SI and ipsilateral MI seen in these monkeys was similar to monkey 32 .

To determine the degree to which this overlap between MI and SI inputs was somatotopically specific, in two monkeys (hemispheres 36L and 37L) we made small injections in the foot region of area 4 and the trunk region of area $3 \mathrm{~b}$ (Fig. 3A). These nonhomologous injection sites labeled projection fields in largely different regions of the putamen. However, the two sets of projection patches sometimes lay adjacent to each other or even partially overlapped (Fig. $3 A^{\prime}$ ). Projections from cortex representing body parts even farther apart in the cortical mapthe foot and the hand-showed this same pattern of predominant but not total segregation (Fig. $3 B^{\prime}$ ).

To study the degree of overlap when larger extents of SI and MI were labeled, in two monkeys (hemispheres 33R and 34R), we made large confluent deposits of one tracer throughout the foot, leg, trunk, arm, and hand representations of SI, and the other tracer throughout the foot and leg representation of MI of the same hemisphere (Fig. 4A). The larger SI injection site labeled regions in the putamen that overlapped with, but were more extensive than, those labeled by the smaller MI injection. The overlap was somatotopically restricted: in the leg region of the ipsilateral putamen, the SI and MI projection patches overlapped, whereas in the trunk and arm regions of the putamen only SI projection patches were labeled. Figure $4 B$ shows an overlay charting of typical pairs of cross sections.

In monkeys in which tracers were deposited in matched body part representations in MI and SI, marked exceptions to the correspondence between MI and SI input zones were rare. However, the precision of alignment of the two sets of projection patches varied. Hemispheres $32 \mathrm{~L}$ and $33 \mathrm{R}$ had very close zonefor-zone correspondence, whereas hemispheres $32 \mathrm{R}$ and $34 \mathrm{R}$ had labeled projection zones that were not always in exact register; they were sometimes either offset slightly from each other or interdigitated with each other. There was a rough correlation between degree of projection-field overlap in the putamen and injection site sizes: in the hemispheres with less precise overlap, the injection sites were somewhat smaller. There was also a rough correlation between degree of overlap of the projections in the putamen and in the sccond somatosensory arca (SII). In hemispheres $32 \mathrm{~L}, 33 \mathrm{R}$, and $34 \mathrm{R}$, the projections from $\mathrm{MI}$ and SI overlapped in SII, but in $32 \mathrm{R}$, they were adjacent to each other, suggesting that in $32 \mathrm{R}$ the $\mathrm{MI}$ and $\mathrm{SI}$ injection sites were not in perfectly matched body part representations (data not shown).

\section{Dense inputs from ipsilateral and contralateral sensorimotor} cortex rarely converge in the putamen

SI and contralateral MI send inputs to predominantly different regions of the putamen. In sharp contrast to the convergence of the ipsilateral projections from MI with those from SI, the most densely labeled projections from contralateral MI tended to innervate zones between or next to ipsilateral SI projection zones.
Typical interdigitation of SI and contralateral MI projections is shown in Figure $4 C$, for monkey 33. In that monkey, we injected ${ }^{35} \mathrm{~S}$-methionine throughout the foot, leg, trunk, arm, and hand representations of the left SI cortex, contralateral to a deposit of WGA-HRP filling the foot and leg MI cortex in the right hemisphere (Fig. 4A). The amount of overlap between the crossprojections (Fig. $4 C$ ) was much less than that seen between the ipsilateral projections labeled in the other hemisphere of the same monkey (Fig. $4 B$, described above). Similar results were obtained in a second monkey (34), in which the samc cxpcrimental design was followed with the tracers reversed.

In both of these monkeys, the zones of the putamen densely labeled by ipsilateral SI and contralateral MI tended to be adjacent to each other, and sometimes the ipsilateral and contralateral projection zones curved around each other as if both were governed by the same boundary conditions. This proximity suggested that the lack of overlap of the hot spots was not simply the result of a wide dispersal of inputs from SI and contralateral MI. The interdigitation of the two corticostriatal projections was not, however, invariant in either monkey: in a few sections in each case, the projection zones labeled from one hemisphere overlapped the projection zones from the other hemisphere. Furthermore, in contrast to the interdigitation of the zones of dense labeling, there was weak labeling surrounding these hot spots that was not well separated. Nonetheless, the tendency for SI and contralateral MI projection patches to avoid each other was dramatically different from the characteristic overlap of SI and ipsilateral MI projections, as can be seen in Figure 4.

Ipsilateral and contralateral MI send inputs to predominantly different regions of the putamen. The results just described suggested that the corticostriatal projections from ipsilateral and contralateral MI form distinguishable input systems in the putamen. To test this conclusion directly, we injected WGA-HRP and ${ }^{35} \mathrm{~S}-\mathrm{methionine}$ in the left and right $\mathrm{MI}$ of monkey 35 , filling all of $\mathrm{MI}$ on both sides (Fig. $5 \mathrm{~A}$ ), except for the face regions (see below). In the putamen of both hemispheres, the dense zones of labeled ipsilateral and contralateral projections from MI predominantly avoided each other. Charts of three sections through the right putamen are shown in Figure $5 B$. The degree of overlap for these ipsilateral and contralateral MI projections was similar to that found in the monkeys with injections of ipsilateral SI and contralateral MI. In contrast to the densely labeled projection zones, the haloes of weak label overlapped, as in the monkeys with $\mathrm{SI}$ and $\mathrm{MI}$ injections.

Judging from the foot-dorsal, head-ventral somatotopic organization of the putamen's motor sector, the degree of overlap of the ipsilateral and contralateral MI projections did not appear to vary with the body part labeled: the leg, trunk, and arm regions showed equivalent small amounts of overlap. However, the face region of MI was not labeled in these hemispheres, and the possibility for variations by body part in this monkey could only be estimated roughly. Consequently, to make comparisons of the projections from ipsilateral and contralateral MI representing individual body parts, we made small injections in single body part representations of MI in three monkeys, again using distinguishable tracers in each pair of hemispheres.

Because the foot and face regions of MI project to parts of the putamen far enough apart that their projections are easy to distinguish from each other, we could inject both regions in a single monkey by reversing the tracers used for each hemisphere. We did this in monkey 40 (Fig. 6), depositing WGA-HRP in the foot region and ${ }^{35} \mathrm{~S}$-methionine in the face region in the left 
hemisphere, and reversing the tracers in the right hemisphere. The relationship between the ipsilateral and contralateral MI projections could thus be compared independently in two different hemispheres for each of the two body parts. The foot region of $\mathrm{MI}$ in both hemispheres sent a contralateral projection that was fainter and had a more lateral distribution in the dorsal putamen than the ipsilateral foot projection. In both hemispheres, the dense contralateral input zones predominantly avoided the zones receiving heavy inputs from the ipsilateral foot region. Figure $6 A^{\prime}$ shows the results for the right hemisphere. The projections from the two MI face cortex injections, in sharp contrast, were squarely overlapping in the putamen on both sides. Figure $6 B^{\prime}$ shows the results for the right hemisphere. The face region of $\mathrm{MI}$ also differed from the foot region in sending relatively stronger cross-projections to the putamen.

In monkey 41 we placed different tracers in the MI trunk region of the two hemispheres (Fig. $7 A$ ). The regions of the putamen labeled by these injections tended to be slightly ventral to those labeled by the foot MI injections, and dorsal to the regions labeled by face $\mathrm{MI}$ injections (compare Figs. $6 A^{\prime}, B^{\prime}$; $\left.7 A^{\prime}\right)$. The trunk region of MI sent stronger cross-projections to the putamen than did the foot region of MI. In both hemispheres the ipsilateral and contralateral $\mathrm{Ml}$ trunk projections predominantly interdigitated, although there was some overlap along the borders of the two projections' most densely labeled zones. Thus, the MI trunk projections avoided each other as had the MI foot projections, rather than overlapping, as had the MI face projections.

Finally, we compared the inputs from the MI hand cortex of the two hemispheres (monkey 42). The regions of the putamen labeled by these injections tended to be slightly ventral to those labeled by the trunk MI injections, and dorsal to the regions labeled by face MI injections (compare Figs. $6 B^{\prime}, 7 A^{\prime}, B^{\prime}$ ). A few projection zones were far dorsal to the main hand projection zone (Fig. $7 \mathrm{~B}$ ). The ipsilateral and contralateral hand MI projections had a relation to each other that was similar to the projections from foot MI: they innervated different zones in the putamen, and the contralateral projection was significantly weaker than the ipsilateral one.

\section{MI innervates discrete zones in the matrix}

In the mid-caudal putamen of the primate-the sector where most of the corticostriatal fibers from SI and MI terminatestriosomes are relatively scarce or difficult to demonstrate. Farther rostrally, however, both striosomes and labeled corticostriatal inputs were clearly visible. For all levels at which both striosomes and labeled projection zones were present, both ipsilateral and contralateral MI projected predominantly to the extrastriosomal matrix (Fig. 8). This preferential targeting of the matrix held not only for hemispheres with relatively small tracer injections in foot, trunk, hand, and face MI, but also for hemispheres in which large tracer deposits filled most of MI. There were occasional exceptions in which small projection zones from motor cortex overlapped striosomes. Such exceptions were more frequent for the contralateral than for the ipsilateral MI projection (see Fig. 8). The SI projection to the putamen, as reported previously (Flahcrty and Graybicl, 1991a), was also dircetcd predominantly towards the matrix.

Even when MI was labeled heavily along most of its length, the labeled systems of zones within the matrix did not fill the matrix completely. Patchiness was most apparent at the borders of the projection, but was apparent at all rostrocaudal levels. Even in the main field of the MI projection (about A 10.0 to A

\section{INJECTION SITES}

\section{A. Foot, trunk}

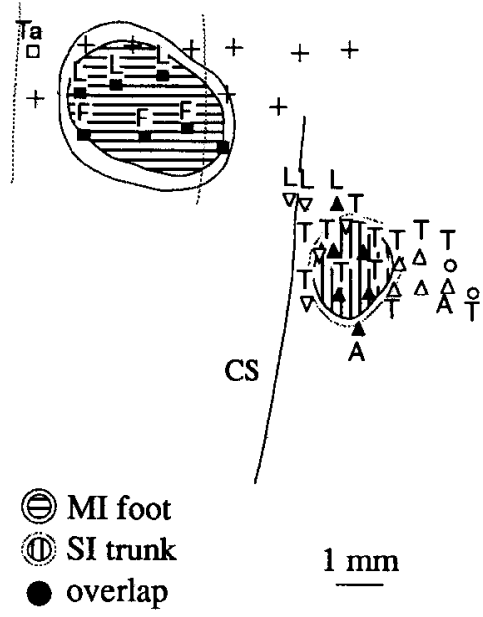

\section{B. Foot, hand}
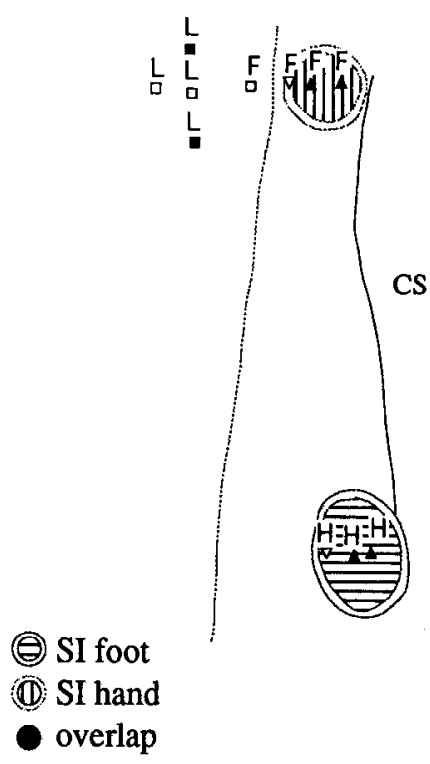

Figure 3. See facing page for caption.

12.0), the matrix was not uniformly labeled. Similarly, when SI was similarly injected with tracer, the labeled corticostriatal projection also did not completely fill the matrix within its target zone. We therefore tested the possibility that the remainder of the matrix in the sensorimotor sector of the putamen might be filled in by the projection of contralateral Ml to nonoverlapping parts of the matrix. We compared closely spaced triplets of sections for the relative distributions of ipsilateral MI projections, contralateral MI projections, and striosomes in the putamen. Even when ipsilateral and contralateral motor cortical projections were combined, there were still regions within the sensorimotor termination zones of the matrix which were not heavily labeled. Figure 9 illustrates this point with an overlay drawing of the triplet of cross sections photographed in Figure 


\section{IPSI. PUTAMEN}
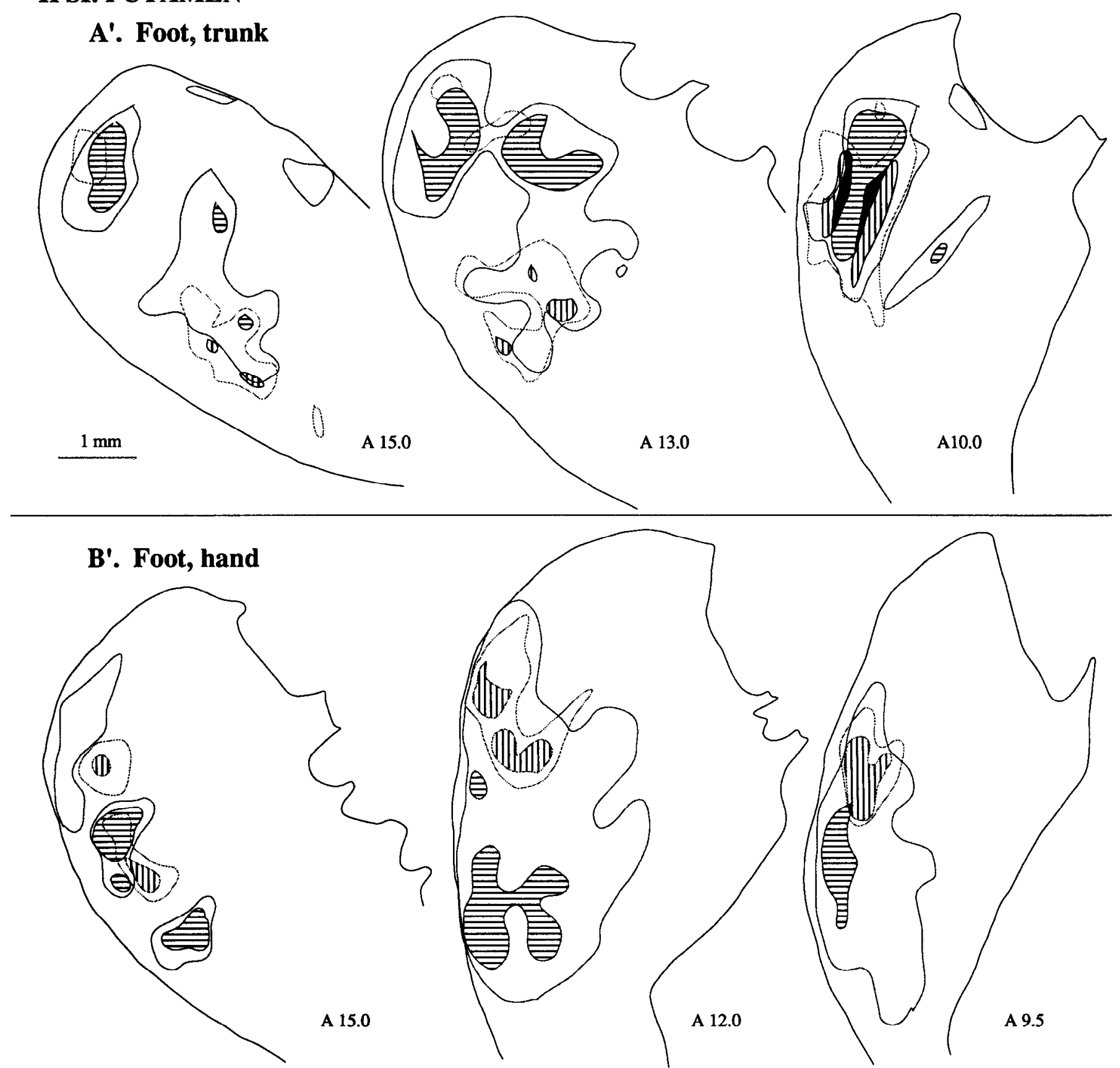

A 15.0
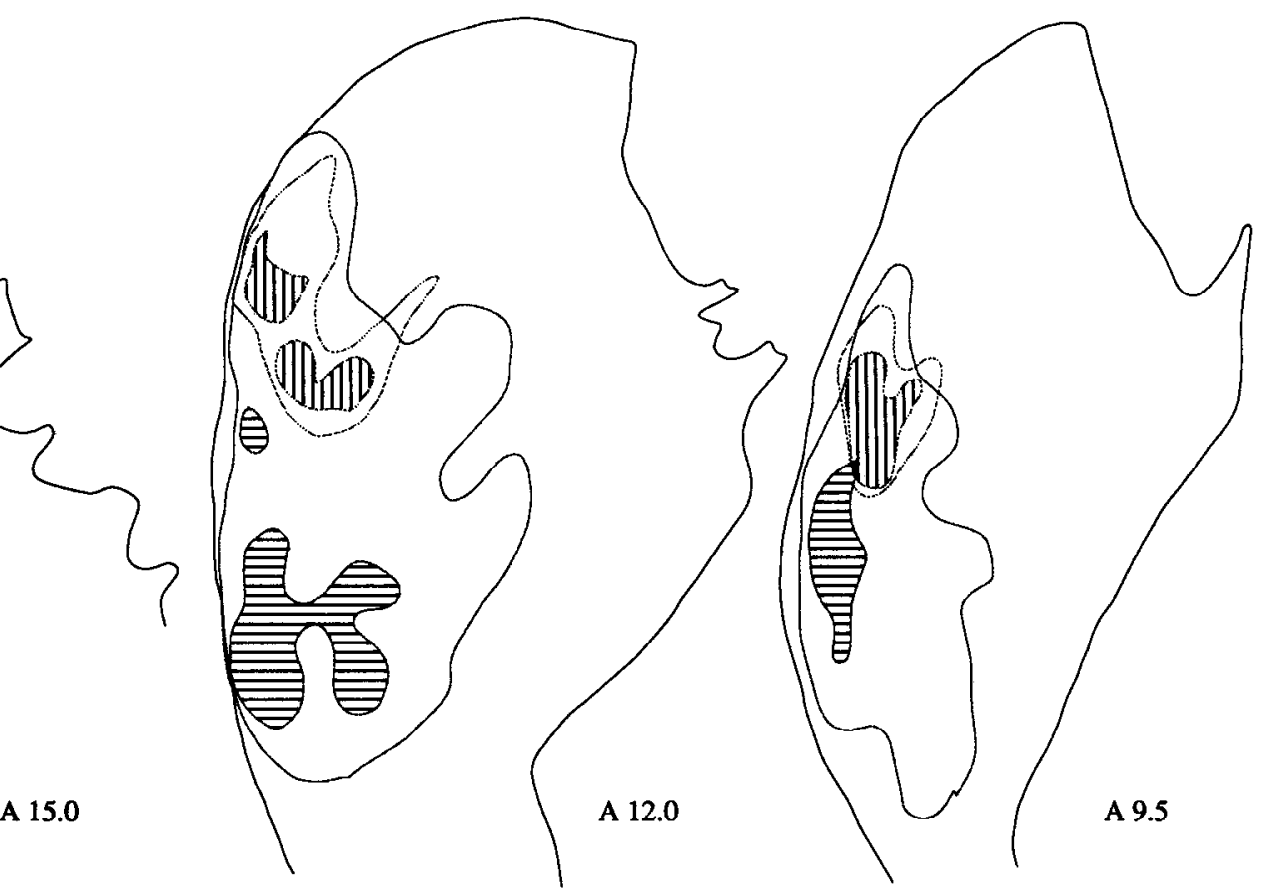

Figure 3. MI and SI regions representing different body parts project to largely but not completely separate regions in the putamen (monkeys $37 \mathrm{~L}$ and $30 \mathrm{R}$ ). $A$ and $B$, Reconstructions of MI and SI tracer injection sites in both hemispheres, superimposed on the stimulation and recording maps. $S y m b o l s$ are explained in the Figure 2 caption. $C S$, central sulcus. Other letters indicate sites of stimulated movement: $T a$, tail; $F$, foot; $L$, leg; $T$, trunk; $A$, arm. $A^{\prime}$ and $B^{\prime}$, Overlay chartings of serial coronal sections through the putamen at three A-P levels, showing the predominant separation of patches from two different body parts, but also the occasional interdigitation or overlap. Atlas coordinates are given below sections. Scale bars in $A$ and $A^{\prime}$ apply to $B$ and $B^{\prime}$, respectively. $B$ and $B^{\prime}$ (monkey 30R) are printed backward for ease of comparison with $A$ and $A^{\prime}$.

$8 A-C$, in which the most intense fields of labeling are charted along with striosomes.

\section{Discussion}

These experiments demonstrate the existence of two sets of motor cortical input zones within the matrix of the squirrel monkey striatum (Fig. 10). The first receives somatotopically matched, largely convergent inputs from ipsilateral MI and SI. The second receives inputs from contralateral MI. Both sets of zones are distinctly modular, and - with the apparent exception of those in the face region of the putamen-the two sets are most often nonoverlapping. Our results suggest that (1) the putamen does not segregate motor and somatosensory information as much as it segregates information about the ipsilateral and contralateral body, (2) the putamen receives more information from contralateral MI about axial body parts than distal ones, and (3) matrisomes receiving motor and somatosensory information about a given body part are positioned such that they 


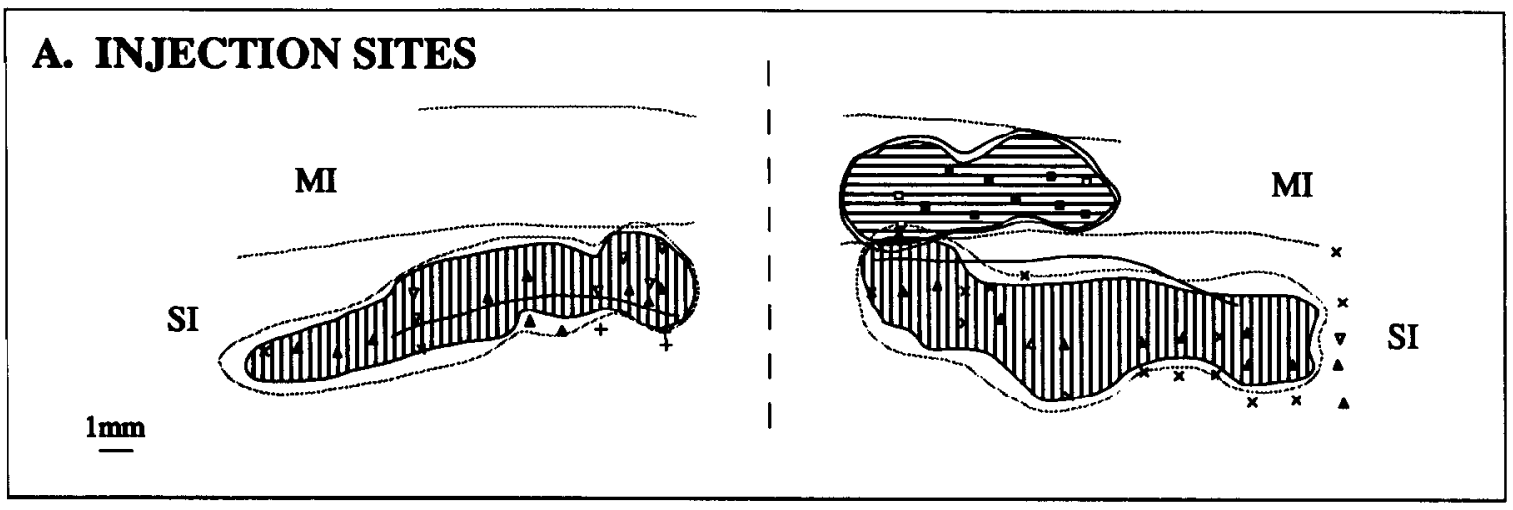

\section{B. IPSI. PROJECTIONS}
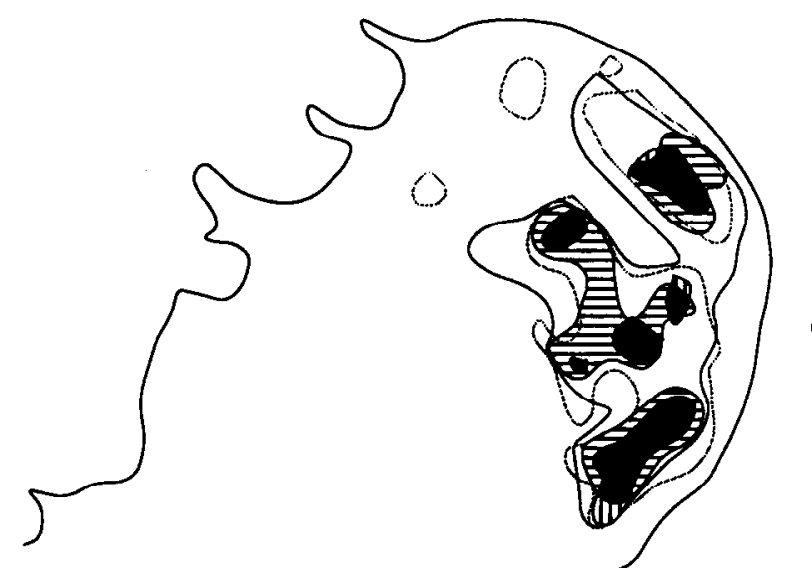

(1D) SI
(O) Ipsi. MI
overlap
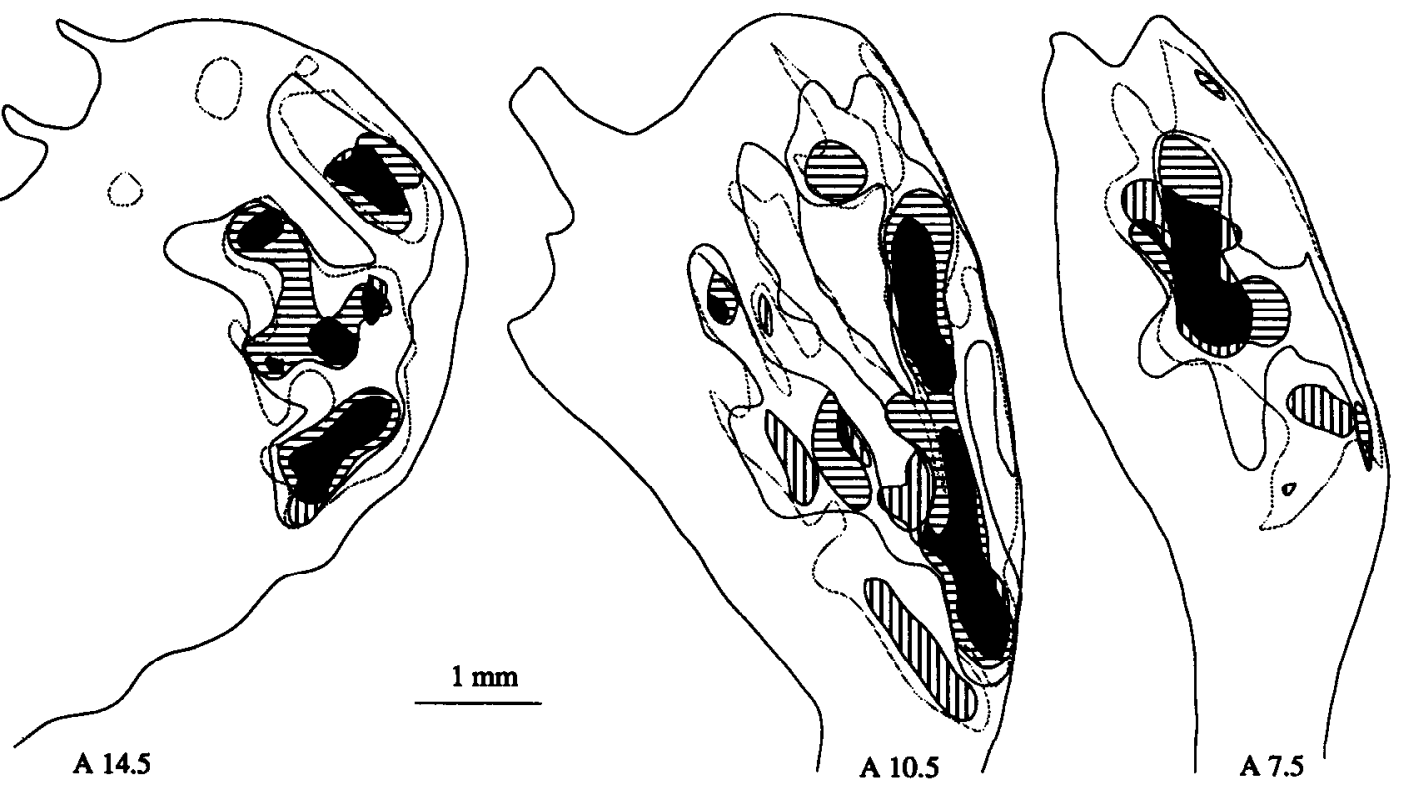

\section{CONTRA. PROJECTIONS}
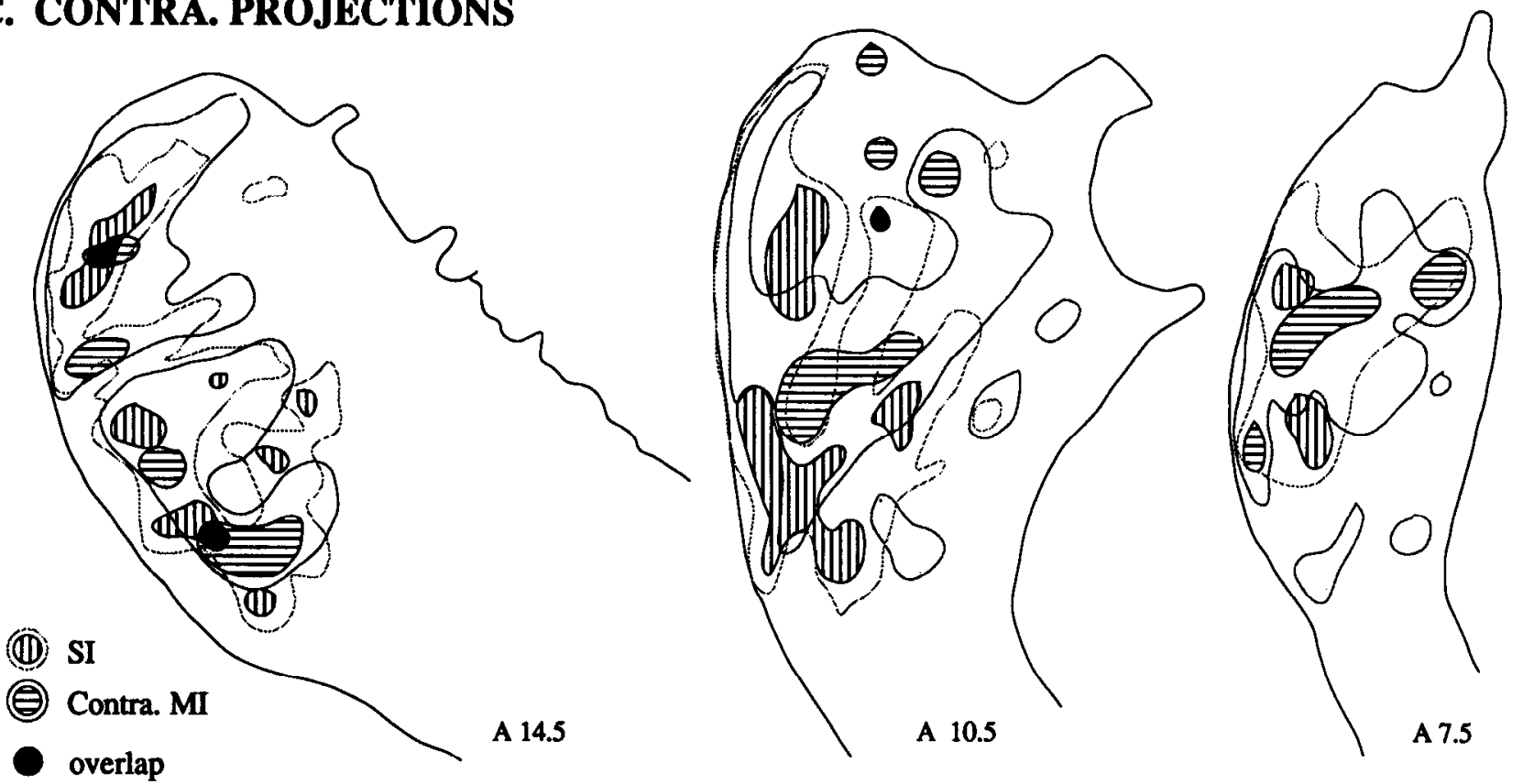


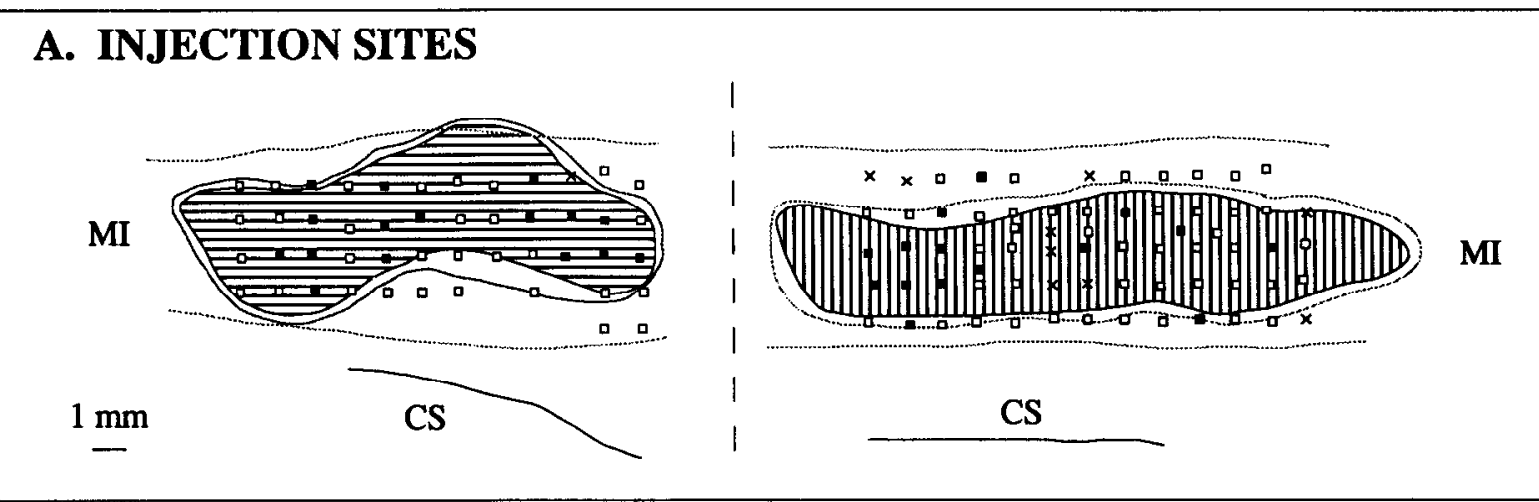

\section{B. PROJECTIONS}
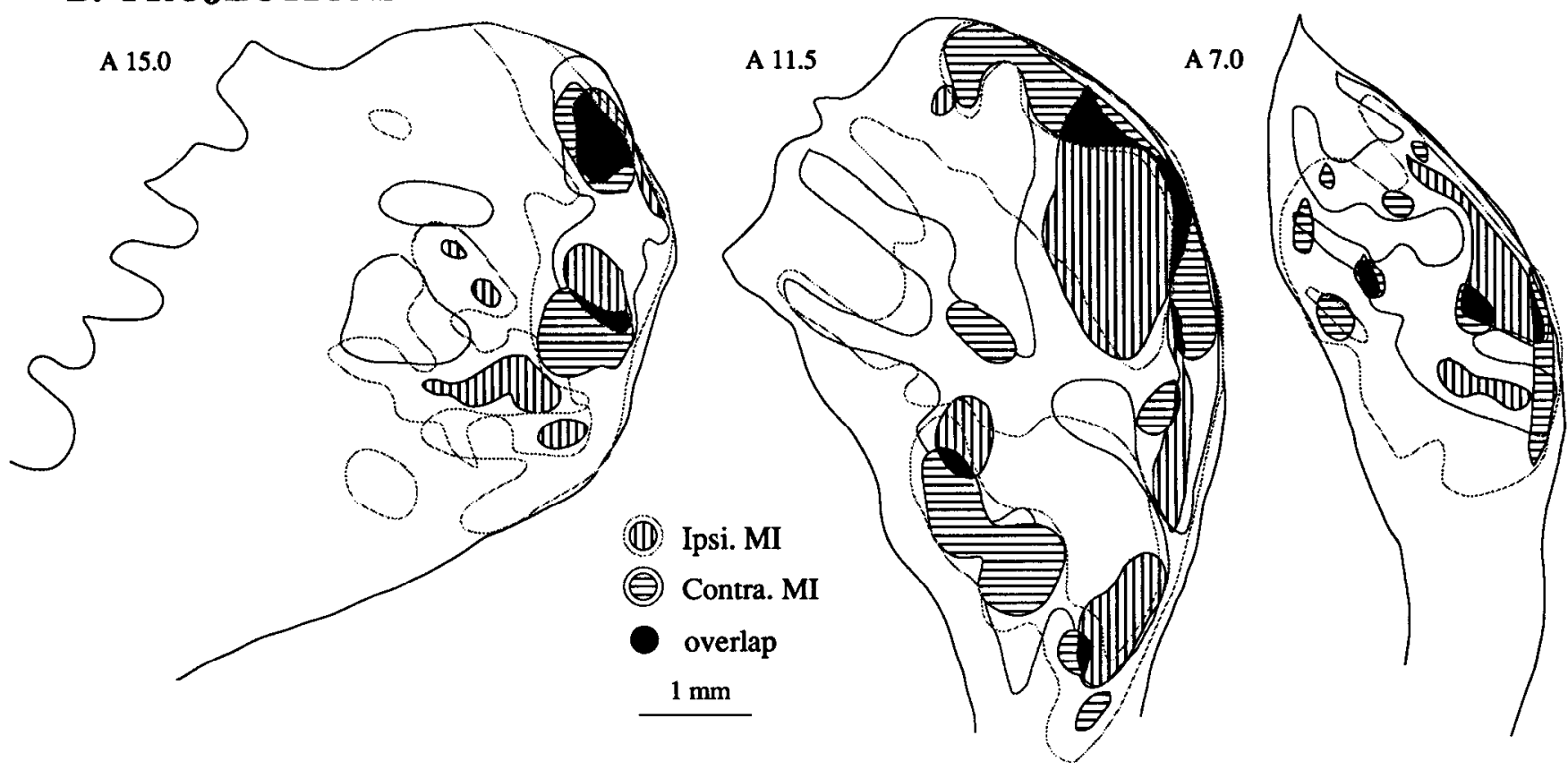

Figure 5. Ipsilateral and contralateral MI project to predominantly segregated regions in the putamen (monkey 35). $A$, Reconstructions of MI tracer injection sites in both hemispheres, superimposed on the stimulation and recording maps. MI was filled bilaterally in the foot, leg, trunk, arm, and hand regions. Abbreviations and symbols are explained in the Figure 2 caption. B, Overlay chartings of serial coronal sections through the putamen at three A-P levels, showing the lack of overlap (black regions) of the two labels transported from ipsilateral and contralateral MI.

can interact along their borders with matrisomes receiving information from nearby ipsilateral body parts, with matrisomes receiving information from the contralateral body part, with other matrisomal systems with unknown inputs, and with striosomes. The sensorimotor input map in the putamen is thus considerably patchier than maps in other CNS representations of the body.

\section{Organization of the matrix in the sensorimotor region of the putamen}

In a previous study we demonstrated that small tracer injections in electrophysiologically identified SI cortex innervate discrete zones within the matrix of the putamen, rather than innervating the matrix uniformly (Flaherty and Graybiel, 1991a). What innervated the adjacent regions of matrix was not identified. We show here that the matrix inputs are patchy even when labeled by extensive injections in SI cortex, as is true also in the cat (Malach and Graybiel, 1986). Ipsilateral MI does not innervate the adjacent matrix; it innervates approximately the same zones as SI does. The projections labeled by injection sites filling all of SI or MI were less patchy in the main field of the projection than in more peripheral parts of the projection field, and contralateral MI innervates some matrix regions adjacent to the ipsilateral MI input zones. But even in monkeys in which very

Figure 4. Although SI and ipsilateral MI project to overlapping regions in the putamen, SI and most of contralateral MI do not (monkey 33). A, Reconstructions of MI and SI tracer injection sites in both hemispheres, superimposed on the stimulation and recording maps. The right MI injection site filled foot and leg regions; the left and right SI injection sites filled foot, leg, trunk, arm, and hand regions. Abbreviations and symbols are explained in the Figure 2 caption. $B$, Overlay chartings of serial coronal sections through the putamen at three A-P levels, showing the overlap (black regions) of the dense zones of the two labels transported from the ipsilateral MI and SI injection sites shown on the right side of A. $C$, Overlay chartings showing the lack of overlap of label transported from the ipsilateral SI injection site shown on the left side of $A$ and the contralateral MI injection site shown on the right side. The scale bar in $B$ applies also to $C$. 


\section{INJECTION SITES}

\section{A. Foot}

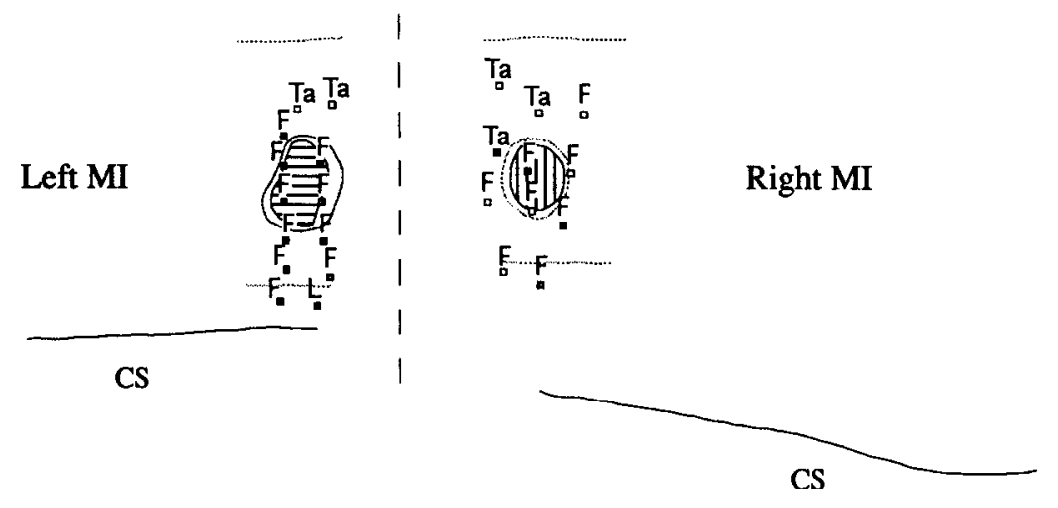

\section{B. Mouth}
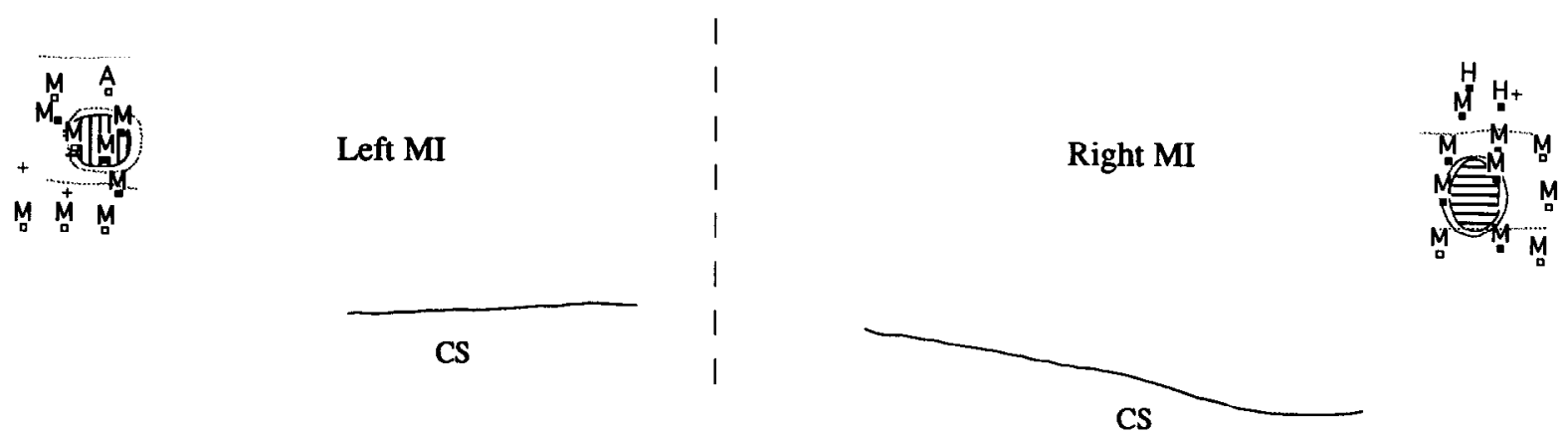

Figure 6. Projections from the foot MI representations interdigitate in the putamen, but those from the mouth representations overlap (monkey 40). $A$ and $B$, Reconstructions of MI tracer injection sites in both hemispheres, showing paired injections of the foot region $(A)$, and mouth region $(B)$. Letters indicate sites of stimulated movement: $T a$, tail; $F$, foot; $T$, trunk; $A$, arm; $H$, hand; $M$, mouth. Other abbreviations and symbols are explained in the Figure 2 caption. $A^{\prime}$ and $B^{\prime}$, Overlay chartings of serial coronal sections through the right putamen at three A-P levels, showing the interdigitation of labeled inputs from the ipsilateral and contralateral MI foot region $\left(A^{\prime}\right)$, in contrast to the overlap (black regions) of the densest regions of labeled inputs from ipsilateral and contralateral MI mouth regions $\left(B^{\prime}\right)$.

large deposits of tracer were placed in MI of both hemispheres, there were still zones of matrix in the sensorimotor part of the putamen in which little labeling appeared. Our findings thus not only establish the presence in the putamen of two sets of matrisomes with different sensorimotor inputs, but also suggest there may be other sets of matrisomes there as well.

It is often assumed that MI projects to the matrix in the primate putamen, as it does in the rat (Donoghue and Herkenham, 1986). The present study provides direct evidence for this assumption. At all levels of the striatum at which both striosomes and MI projections were visible, both ipsilateral and contralateral motor cortex projections predominantly avoided striosomes. There were occasional exceptions to this rule, more often in the contralateral than in the ipsilateral projection. However, most of the inputs to the putamen from MI on both sides terminated in discrete zones outside striosomes.
The existence of multiple distinguishable matrisomal systems raises again the question first raised when striosomes were discovered: what is the purpose of all this patchiness in the striatum? Recent evidence suggests that the outputs of the striatal matrix are as patchy as its inputs (Desban et al., 1989; JiménezCastellanos and Graybiel, 1989; Giménez-Amaya and Graybiel, 1990; Selemon and Goldman-Rakic, 1990). The next step in studying this mosaic, therefore, will be to determine the relations between these input and output zones.

\section{Convergence of ipsilateral SI and MI inputs to the putamen}

In previous work we showed that in the squirrel monkey there is convergence onto the putamen of different SI maps: areas 3a, $3 \mathrm{~b}$, and 1 scnd somatotopically organized, largely overlapping inputs to the putamen (Flaherty and Graybiel, 1991a). Thus, the evidence we present here for SI and ipsilateral MI conver- 

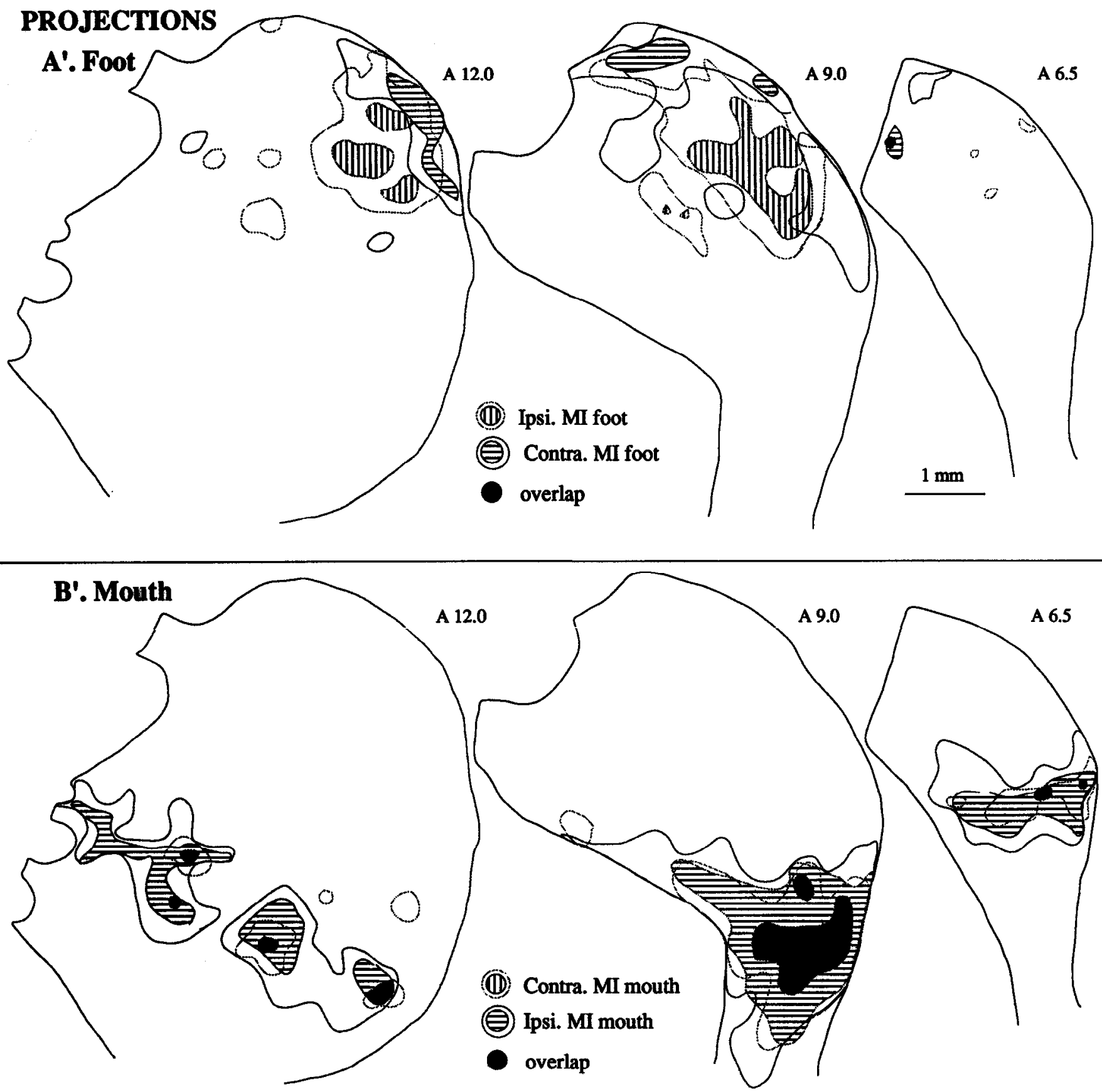

Figure 6. Continued.

gence suggests that there is a set of matrisomes in the ipsilateral striatum that receives input from somatotopically related parts of the four adjacent body maps in areas $4,3 a, 3 b$, and 1 . We found convergence of labeled SI and MI inputs both in monkeys in which relatively small injections were centered in one body part, and in monkeys in which much larger injection sites were made. Because the overlap occurred for the projections of all pairs of matched body representations we tested, convergence may be a general rule for all of the MI and SI projection fields. This hypothesis is consistent with the findings of Fotuhi et al. (1989), who noted overlap of corticostriatal inputs from regions of MI and SI cortex injected without electrophysiological guidance.

Three-dimensional reconstructions indicate that these matrisomes have branching, often discontinuous structures (Malach and Graybiel, 1986; Flaherty and Graybiel, 1991a). Single body part representations in the cortex thus send projections to extended and probably multiple domains within the sensorimotor sector of the ipsilateral putamen. Electrophysiological recording experiments support the claim that these ipsilateral inputs carry information about the contralateral body (Crutcher and DeLong, 1984; Liles and Updyke, 1985), and that in the monkey, to a greater extent than in the rat, the neural signaling in these fibers may be different from that in corticospinal fibers sent to the spinal cord (Donoghue and Kitai, 1981; Bauswein et al., 1989). It is still unclear whether the matrisomal organization of these corticostriatal projections reflects the presence of a single, discontinuous body map in the putamen or whether the separate input zones are parts of separate, functionally differentiated body maps in the putamen. Like the "fractured somatotopy" de- 


\section{INJECTION SITES}

\section{A. Trunk}
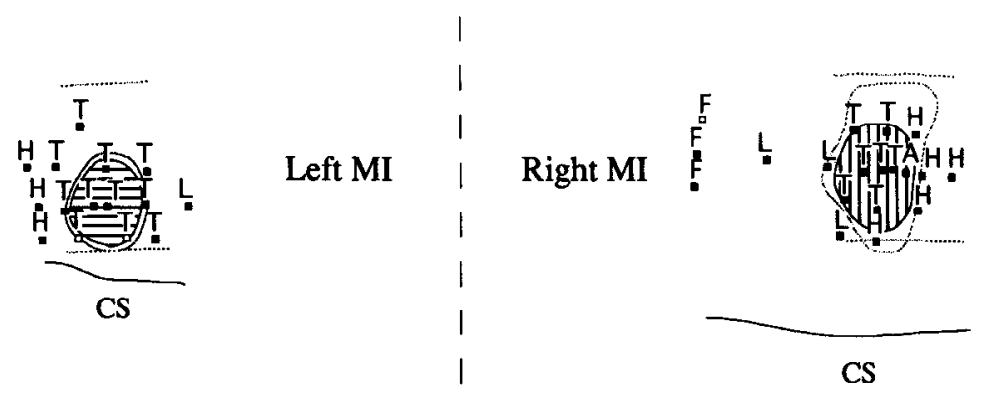

$1 \mathrm{~mm}$

\section{B. Hand}

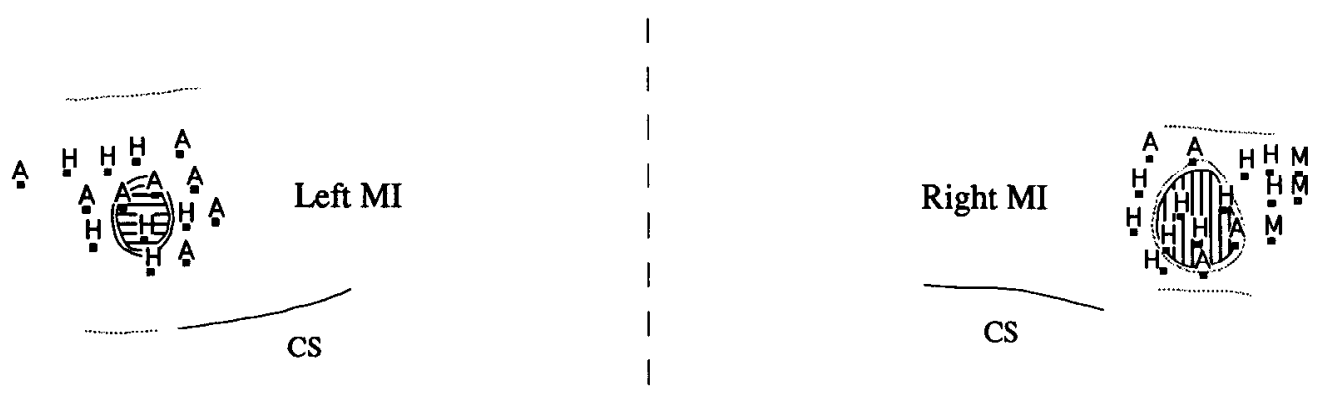

Figure 7. Projections from the ipsilateral trunk and hand MI representations to the putamen interdigitate with their homologs from contralateral MI (monkeys 41,42$). A$ and $B$, Reconstructions of the MI tracer injection sites in both hemispheres, showing paired injections of the trunk region $(A)$, and hand region $(B)$. Abbreviations and symbols are explained in Figure 2 and 6 captions. $A^{\prime}$ and $B^{\prime}$, Overlay chartings of serial coronal sections through the right putamen at three A-P levels, showing the interdigitation of the densest regions of labeled inputs from ipsilateral and contralateral MI trunk regions $\left(A^{\prime}\right)$, similar to the interdigitation of labeled inputs from the ipsilateral and contralateral MI hand region $\left(B^{\prime}\right) . B$ and $B^{\prime}$ are printed in reverse, for ease of comparison with $A$ and $A^{\prime}$

scribed for the cerebellum (Kassel et al., 1984), the map or maps in the putamen are discontinuous in that multiple patches representing unrelated body parts are intermingled. Unlike the cerebellum, however, the putamen contains regions with sensorimotor input that are interrupted by tissue with no strong sensorimotor input (Figs. 4, 9) or responsiveness (Crutcher and DeLong, 1984; Alexander and DeLong, 1985b). In addition, unlike the fractured representations in the cerebellum, individual putamen sensorimotor zones have so far not been shown to have a finer-grained somatotopy within them.

Our findings suggest that the corticostriatal projection transforms cortical body maps in at least two respects (Fig. 10). First, inputs from cortical areas with different sensorimotor roles, such as the motor map of area 4, the deep receptor map of area 3a, and the cutaneous map of area $3 \mathrm{~b}$ - maps that are kept physically separate in the cortex-project to the same regions of the putamen. Second, the relatively continuous cortical maps are reorganized into a patchy map or maps in the putamen. Patchy somatotopic representations may be more efficient than continuous ones in performing sensorimotor computations that involve nonlocal as well as local interactions (Nelson and Bower, 1990). These two differences, then, may reflect fundamental differences in the constraints and goals of movement control by the sensorimotor cortex and the putamen. 

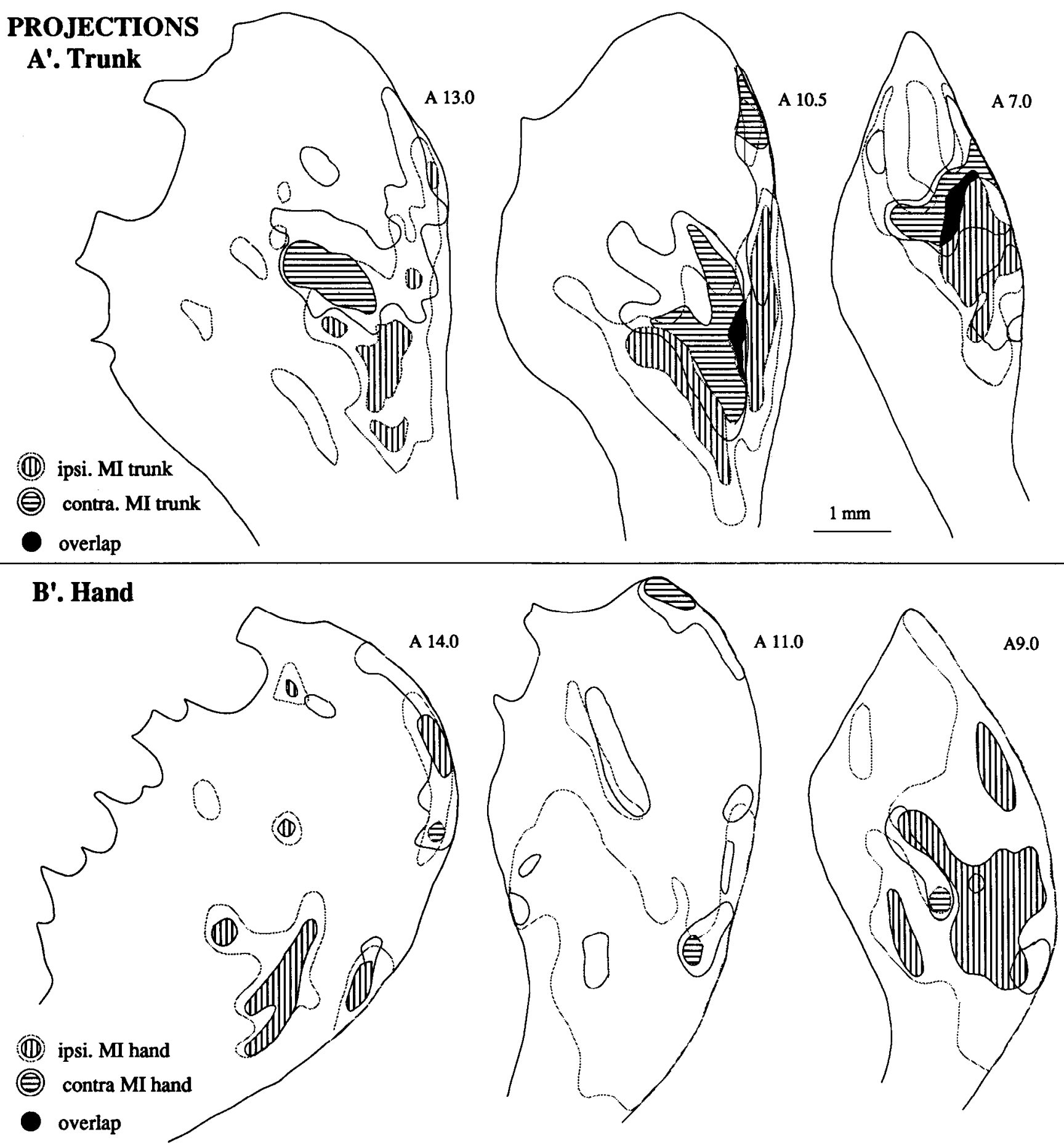

Figure 7. Continued.

Although somatotopically organized convergence was the rule for ipsilateral MI and SI inputs to the putamen, the rule was not always followed perfectly. We were interested in the nature of the exceptions, which fell into roughly three categories: lack of overlap between some projection fields from the same body part representations in different cortical maps, overlap between projections from different body part representations, and changes in degree of overlap at different A-P levels.

We considered several factors that could account for such exceptions. First, larger injection sites labeled projections that overlapped each other somewhat more than smaller ones, sug- gesting that the precision with which exactly matched body part representations were injected at the small sites could have been a factor. We therefore used projections from MI and SI to SII as an independent check of our injection site reconstructions. Because SII has somatotopically organized connections with SI and MI (Friedman et al., 1980; Yumiya and Ghez, 1984; Mori et al., 1989), lack of overlap of labeled regions in SII indicates an imperfect match between body part representations injected in MI and SI. This was seen in only one hemisphere, 32R. Second, the occasional failure in overlap might instead have reflected differences in the A-P location of the $\mathrm{MI}$ injection sites, 

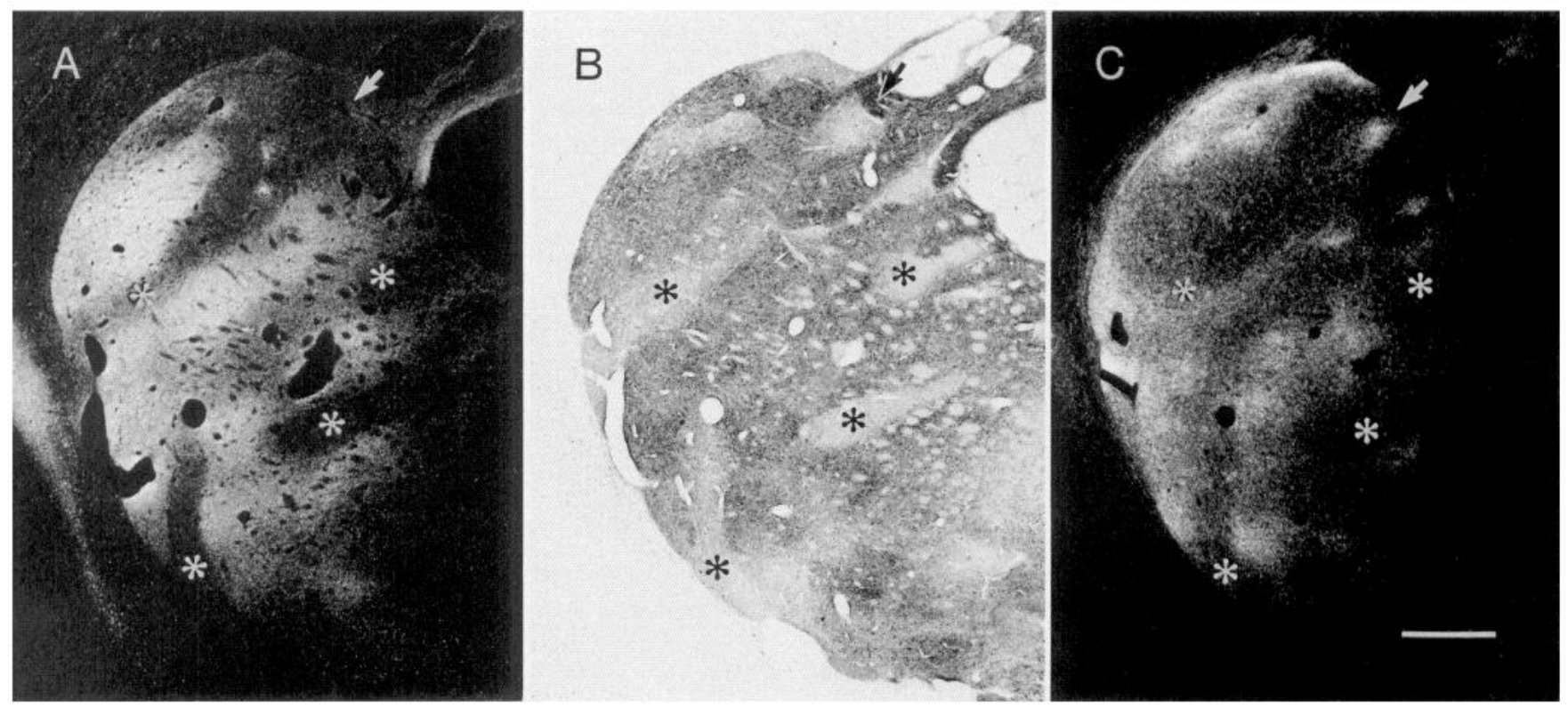

Figure 8. Ipsilateral and contralateral MI send projections to multiple matrisomes in the extrastriosomal matrix of the putamen (monkey 35 ). Asterisks mark locations of striosomes in $B$ and corresponding locations in $A$ and $C$. A, A coronal section through the putamen at $\mathrm{A}$ 14.0, showing inputs to the putamen from ipsilateral MI, labeled with WGA-HRP. $B$, Striosomes in a putamen section serial to that shown in $A$. Striosomes appear as regions of weak met-enkephalin immunostaining. $C$, Inputs from contralateral MI, labeled with ${ }^{35} S$-methionine. Arrows mark the location of an exception, in which contralateral MI innervates a small striosome. Scale bar, $1 \mathrm{~mm}$.

as anterior and posterior MI differ in their connections, cytoarchitecture, and electrophysiology (Strick and Preston, 1978a,b; Tanji and Wise, 1981; Gould et al., 1986; Holsapple et al., 1991). However, our injection sites included most of the A-P extent of MI in most monkeys, and there was no obvious correlation between the A-P locations of the injection sites and the degree of MI and SI projection overlap in the putamen. Third, the imperfect overlap between SI and MI projections from homologous representations may reflect the fact that SI

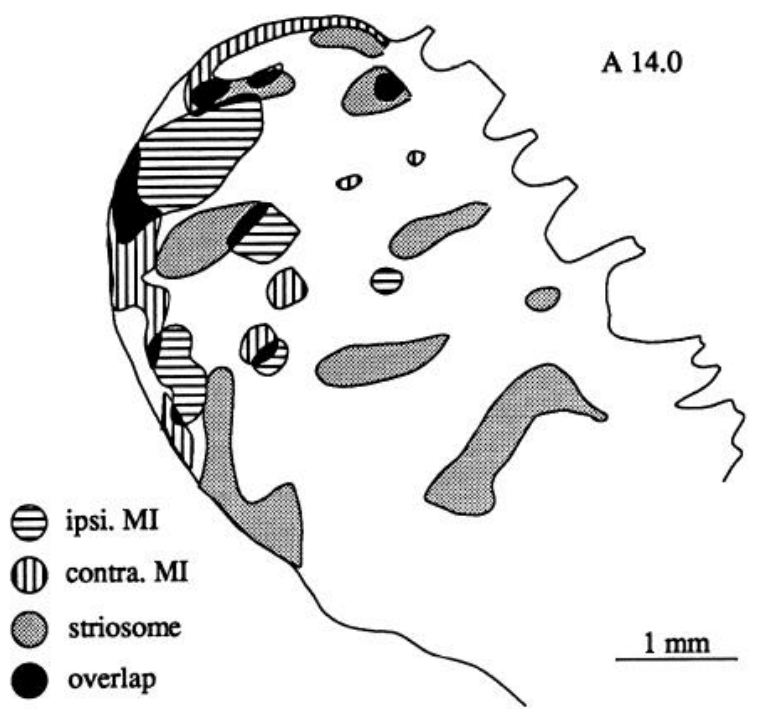

Figure 9. Ipsilateral and contralateral MI projections do not uniformly fill the matrix, and form separate subsystems within it. Shown is an overlay charting of the three putamen sections photographed in Figure 8 , showing the location of the densest zones of the ipsilateral and contralateral inputs from MI with respect to striosomes. and MI representations are never perfectly homologous. The relatively strict cutaneous somatotopy of SI area $3 \mathrm{~b}$, for instance, can only roughly parallel the agonist and antagonist muscle representations in area 4.

Overlap between corticostriatal projections from different body part representations was uncommon for the dense zones of the projections, but was the rule for the faint haloes of label surrounding these dense zones. This overlap of weakly labeled zones occasionally was present even when the body parts were as distant as foot and hand. It is not known whether any individual neurons within these zones receive inputs related to more than one such body part, or whether such convergence is functional-for instance, it might normally be suppressed by lateral inhibition. On the other hand, the overlap might be functionally important in allowing interactions between information about different body parts, or in permitting plasticity in the representations of body parts as has been documented for SI and MI (Jenkins et al., 1990; Jacobs and Donoghue, 1991).

The overlap of body-part input fields varied at different A-P levels of the putamen, as it does in the cat and rat (Malach and Graybiel, 1986; Brown, 1991). Even the foot-dorsal, head-ventral somatotopy was not entirely constant along the A-P axis. For instance, occasional "foot matrisomes" were ventral to some "trunk matrisomes," and even to some "hand matrisomes." This could allow different interactions between inputs at different A-P levels, and might underlie differences in sensorimotor processing in anterior and posterior parts of the putamen. We have already noted some differences in the degree of overlap of corticostriatal inputs from cortical areas within SI itself (Flaherty and Graybiel, 1991a). It is important to emphasize that our experimental protocol limited us to categorizing cortical sites by somatotopy. Another criterion, for instance, categorizing them by directional population coding in MI (Georgopoulos et al., 1989), might have yielded a different set of overlap and neighbor relations between the input patches. 


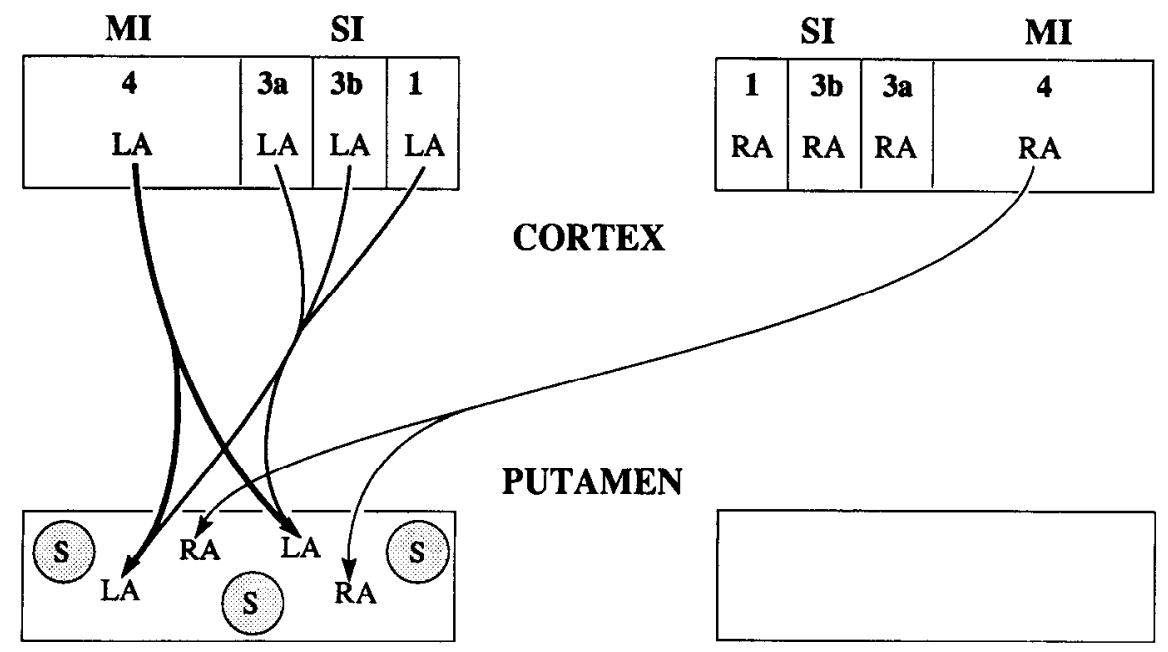

Figure 10. A summary of the sensorimotor cortical arm region inputs to the left putamen; inputs to the right putamen are not shown. Five aspects of the corticostriatal map transformations are shown. (1) Different ipsilateral cortical representations of sensory and motor modalities (areas 4, 3a, 3b, and 1) are combined in the putamen. (2) MI inputs are stronger than SI inputs, and only the former are bilateral. (3) Single cortical representations innervate multiple, patchy zones in the putamen. (4) The input patches are within, but do not fill, the matrix. (5) The inputs interdigitate with patchy inputs from other, unrelated body parts in ipsilateral MI, with inputs from contralateral MI, with matrix regions that do not receive sensorimotor cortex inputs, and with striosomes. $L A$, left arm representation; $R A$, right arm representation; $S$, striosome.

\section{Nonconvergence of contralateral MI inputs to the putamen with ipsilateral $M I$ and SI inputs}

The second set of input matrisomes that we identified was innervated by afferents from contralateral MI. Like the ipsilateral MI projection, the projection from contralateral MI to the putamen was divergent, innervating branched and usually multiple matrisomes. These zones tended to be spatially separate from the hot spots of ipsilateral MI and SI inputs, although often the haloes of weaker labeling were not well separated. 'The contralaterally labeled input matrisomes resembled the ipsilateral ones in being broadly distributed throughout the putamen, but the contralaterally labeled matrisomes tended more frequently to be along the lateral border of the putamen than did the ipsilateral ones. This relative shift is reminiscent of that reported for the rat, in which contralaterally activated sensorimotor zones appear to be displaced in the caudoputamen with respect to ipsilateral ones (Brown, 1991).

Variation with body part representation of $M I$ corlicostriatal projections. The relative strength of the MI corticostriatal crossprojection varied with body part representation. Regions of cortex representing axial muscles - the face and trunk regions - had stronger cross-projections than did those representing appendicular muscles - the foot and hand regions. In this regard, MI's corticostriatal projection resembles its corticocortical projections to contralateral MI, because MI cortex representing trunk and face has stronger callosal connections than does that representing foot and hand representations.

The most dramatic variation with body part representation was the difference between the face and other parts of the MI map in the degree of ipsilateral and contralateral MI projection overlap in the putamen. The consistent overlap of left and right MI face projections contrasted strongly with the predominant nonoverlap of paired inputs traced from other MI sites. This difference was documented in the projection patterns in single hemispheres, and not simply in cross-animal comparisons, but our findings are so far limited to two hemispheres (monkey 40). However, such a pronounced variation in innervation by inputs carrying information about different body parts points to the danger of generalizing about an entire body representation from information about a single part of it.
Overlap in the putamen between inputs from left and right face MI, but not between inputs from hand or foot MI, might reflect a difference between central control of axial versus appendicular movements. Left and right MI trunk projections did overlap to some extent, but the overlap was much less than that between left and right mouth projections. In addition, the trunk projections tended to overlap only along their borders, whereas the mouth projections overlapped squarely: the left and right mouth projections seemed to be centered on the same matrisomes. This difference could reflect interesting differences between the neural processing of face and trunk inputs by the basal ganglia.

Body representations in the putamen. The main representation in MI cortex is of the contralateral body. If the corticostriatal projections from MI carry that information to the putamen, then our results suggest the presence of two body maps in the putamen-one receiving inputs from ipsilateral MI and SI and representing the contralateral body, and the other receiving inputs from contralateral $\mathrm{MI}$ and representing the ipsilateral body.

Electrophysiological recording shows that inputs from ipsilateral sensorimotor cortex create a representation of the contralateral body in the putamen, but the effects of contralateral MI inputs have not been well studied. Stimulation of the putamen of alert monkeys sometimes produces bilateral movements (Alexander and DeLong, 1985a), and in the striatum of alert cats and rats, neurons with bilateral receptive fields have bcen recorded (Schneider and Lidsky, 1981; West et al., 1990). Monkeys given 1-methyl-4-phenyl-1,2,3,6-tetrahydropyridine (MPTP) show an increased number of pallidal neurons with bilateral somatosensory receptive fields (Filion et al., 1988)possibly because there is decreased dopaminergic inhibition of crossed sensorimotor inputs. These crossed inputs need not be originating in $\mathrm{MI}$, however. The supplementary motor area (SMA), for instance, has a role in bilateral movements (see, e.g., Brinkman, 1984), and sends overlapping bilateral projections to the striatum (McGuire et al., 1991). Initial reports suggest that SMA and ipsilateral MI project to separate regions of the striatum (Alexander et al., 1988) and receive inputs via the thalamus from different regions of the globus pallidus (Hoover and Strick, 1991). Our findings raise the possibility that SMA 
projects to the same matrisomes in the putamen as contralateral MI inputs do.

The tendency for right and left MI input matrisomes to alternate in the putamen could bring representations of the homologous parts of the right and left sides of the body into proximity. In some respects the roughly alternating matrisomes are reminiscent of ocular dominance columns (slabs) in the visual cortex. In that system, right and left eye inputs carrying information about approximately the same part of visual space innervate adjoining cortical columns, and processing operations are carried out across pairs of columns (Hubel and Wiesel, 1962). The placement of the left and right input matrisomes does not appear to be a strict alternation, however, nor are the two inputs equally strong. Even so, such a system of nearby left and right input matrisomes might facilitate the control of bilateral movements.

Some neurons in MI fire in relation to movements of the ipsilateral body-especially units in the face region (Huang et al., 1988; Tanji et al., 1988). Thus, another possible interpretation of our findings is that the contralateral MI inputs to the putamen are selectively from the neurons in MI representing the ipsilateral body. If the ipsilateral and contralateral inputs do carry information about the same side of the body, then their segregation in the putamen suggests either that they form two maps, perhaps dealing with different features of the representation, or that they combine to form a single map having inhomogeneous input regions. It would clearly be of interest to identify the cells of origin of the two projections.

\section{Relation between corticocortical and corticostriatal projections}

Our findings indicate that MI's crossed corticostriatal projection is similar to its callosal corticocortical projections in being stronger for regions of MI representing axial body parts than for MI regions representing appendicular ones. Some years ago, Yeterian and van Hoesen proposed that cortically interconnected areas project to overlapping zones in the striatum, whereas cortical areas that are not interconnected do not (Yeterian and Van Hoesen, 1978). Selemon and Goldman-Rakic later reported exceptions to this proposed rule in monkeys in which large cortical injections had been made (Selemon and Goldman-Rakic, 1985), but there is renewed interest in Yeterian and van Hoesen's hypothesis, as it seems to apply to certain cortical regions (Yeterian and Pandya, 1991; Parthasarathy et al., 1992). McGuire and colleagues have proposed the alternate hypothesis that projections from homotopic cortical regions-the same areas in different hemispheres-overlap in the striatum, whereas heterotopic ones do not (McGuire et al., 1991).

The present experiments, however, provide counterexamples to both proposed schemes. First, although MI and SI, and areas 3a, 3b, and 1 within SI (Flaherty and Graybiel, 1991a), are not homotopic, they send convergent inputs to the striatum. Second, ipsilateral and contralateral area 4 are not only cortically connected but also homotopic, yet their inputs to the striatum are predominantly nonoverlapping, unlike those of ipsilateral and contralateral SMA. Third, of the cortical regions with convergent striatal inputs, areas 4 and $3 b$ are apparently not cortically connected (Jones et al., 1978). Projections from area 3a to rostral area 4 have been noted (Ghosh et al., 1987; Huerta and Pons, 1990). We did not attempt to analyze these corticocortical projections because the tracer injections made here were not confined to single areas within SI. However, any spread of the $3 b$ tracer deposit into parts of area $3 \mathrm{a}$ in the present experiments would not change the position of the labeling in the putamen, because the projection from areas $3 a$ and $3 \mathrm{~b}$ themselves converge.

It appears, then, that neither patterns of cortical connectivity nor homotopical relationships are infallible predictors of corticostriatal overlap. We suggest that whether inputs from particular cortical regions converge in the striatum depends on aspects of their functions, which are only sometimes mirrored by their cortical connectivity. Such an organization would allow for different demands of cortical and striatal processing, and for those demands to influence the patterns of connectivity.

\section{References}

Alexander GE, DeLong MR (1985a) Microstimulation of the primate striatum: I. Physiological properties of striatal microexcitable zones. J Neurophysiol 53:1417-1432.

Alexander GE, DeLong MR (1985b) Microstimulation of the primate neostriatum: II. Somatotopic organization of striatal microexcitable zones and their relation to neuronal response properties. J Neurophysiol 53:1433-1446.

Alexander GE, Koliatsos VE, Martin LJ, Hedreen J, Hamada I, DeLong MR (1988) Organization of primate basal ganglia "motor circuit": 1. Motor cortex (MC) and supplementary motor area (SMA) project to complementary regions within matrix compartment of putamen. Soc Neurosci Abstr 14:720.

Bauswein E, Fromm C, Preuss A (1989) Corticostriatal cells in comparison with pyramidal tract neurons: contrasting properties in the behaving monkey. Brain Res 493:198-203.

Brinkman C (1984) Supplementary motor area of the monkey's cerebral cortex: short- and long-term deficits after unilateral ablation and the effects of subsequent callosal section. J Neurosci 4:918-929.

Brown LL (1991) Somatotopic maps in rat striatum: evidence that the striatum plays a role in coordination of the two sides of the body. Soc Neurosci Abstr 17:453.

Crutcher MD, Alexander GE (1990) Movement-related neuronal activity selectively coding either direction or muscle pattern in three motor areas of the monkey. J Neurophysiol 64:151-163.

Crutcher MD, DeLong MR (1984) Single cell studies of the primate putamen. I. Functional organization. Exp Brain Res 53:233-243.

Desban M, Gauchy C, Kemel ML, Besson MJ, Glowinski J (1989) Three-dimensional organization of the striosomal compartment and patchy distribution of striatonigral projections in the matrix of the cat caudate nucleus. Neuroscience 29:551-566.

Donoghue JP, Herkenham M (1986) Neostriatal projections from individual cortical fields conform to histochemically distinct striatal compartments in the rat. Brain Res 365:397-403.

Donoghue JP, Kitai ST (1981) A collateral pathway to the neostriatum from corticofugal neurons of the rat sensory-motor cortex: an intracellular HRP study. J Comp Neurol 201:1-13.

Donoghue JP, Leibovic S, Sanes JN (1992) Organization of the forelimb area in squirrel monkey motor cortex: representation of digit, wrist, and clbow muscles. Exp Brain Res 89:1-19.

Filion M, Tremblay L, Bédard PJ (1988) Abnormal influences of passive limb movement on the activity of globus pallidus neurons in parkinsonian monkeys. Brain Res 444:165-176.

Flaherty AW, Graybiel AM (1990) Proprioception and the striatum: primate somatosensory cortical area 3 a projects more broadly to the striatum than do areas $3 b$ or 1 . Soc Neurosci Abstr 16:1231.

Flaherty AW, Graybiel AM (1991a) Corticostriatal transformations in the primate somatosensory system. Projections from physiologically mapped body-part representations. J Neurophysiol 66:12491263.

Flaherty AW, Graybiel AM (1991b) A second input system for body representations in the primate striatal matrix. Soc Neurosci Abstr 17: 1299.

Fotuhi M, Koliatsos VE, Alcxander GE, DeLong MR (1989) Pattcrns of sensorimotor integration in the primate neostriatum: primary somatosensory cortex (SC) and motor cortex (MC) project to coextensive territories in the putamen. Soc Neurosci Abstr 15:285.

Friedman DP, Jones EG, Burton H (1980) Representation pattern in 
the second somatic sensory area of the monkey cerebral cortex. J Comp Neurol 192:21-41.

Georgopoulos AP, Lurito JT, Petrides M, Schwartz AB, Massey JT (1989) Mental rotation of the neuronal population vector. Science 243:234-236.

Gerfen CR (1989) The neostriatal mosaic: striatal patch-matrix organization is related to cortical lamination. Science 246:385-388.

Gergen JA, MacLean PD (1962) A stereotaxic atlas of the squirrel monkey's brain (Saimiri sciureus). Bethesda: National Institutes of Health.

Ghosh S, Brinkman C, Porter R (1987) A quantitative study of the distribution of neurons projecting to the precentral motor cortex in the monkey (M. fascicularis). J Comp Neurol 259:424-444.

Giménez-Amaya J-M, Graybiel AM (1990) Compartmental origins of the striatopallidal projection in the primate. Neuroscience 34:111126.

Gould HJ, Cusick CG, Pons TP, Kaas JH (1986) The relationship of corpus callosum connections to electrical stimulation maps of motor, supplementary motor, and the frontal eye fields in owl monkeys. J Comp Neurol 247:297-325.

Graybiel AM, Chesselet M-F (1984) Compartmental distribution of striatal cell bodies expressing met-enkephalin-like immunoreactivity. Proc Natl Acad Sci USA 81:7980-7984.

Graybiel AM, Flaherty AW, Giménez-Amaya J-M (1991) Striosomes and matrisomes. In: The basal ganglia, III (Bernardi G, Carpenter MB, di Chiara G, Morelli M, Stanzione P, eds), pp 3-12. New York: Plenum.

Holsapple JW, Preston JB, Strick PL (1991) The origin of thalamic inputs to the 'hand' representation in the primary motor cortex. J Neurosci 11:2644-2654.

Hoover JE, Strick PL (1991) Transneuronal transport of HSV-1 from the primary motor cortex and the SMA: evidence for separate "motor" circuits within the basal ganglia. Soc Neurosci Abstr 17:453.

Huang CS, Sirisko MA, Hiraba H, Murray GM, Scsslc BJ (1988) Organization of the primate face motor cortex as revealed by intracortical microstimulation and electrophysiological identification of afferent inputs and corticobulbar projections. J Neurophysiol 59:796-818.

Hubel DH, Wiesel TN (1962) Receptive fields, binocular interaction, and functional architecture in the cat's visual cortex. J Physiol (Lond) 160:106-154.

Huerta MF, Pons TP (1990) Primary motor cortex receives input from area $3 \mathrm{a}$ in macaques. Brain Res 537:367-371.

Illing RB, Graybiel AM (1986) Complementary and non-matching afferent compartments in the cat's superior colliculus: innervation of the acetylcholinesterase-poor domain of the intermediate gray layer Neuroscience 18:373-394.

Illing RB, Wässle H (1979) Visualization of the HRP reaction product using the polarization microscopc. Ncurosci Lett 13:7-11.

Jacobs KM, Donoghue JP (1991) Reshaping the cortical motor map by unmasking latent intracortical connections. Science 251:944-947.

Jenkins WM, Merzenich MM, Ochs MT, Allard T, Guic-Robles E (1990) Functional reorganization of primary somatosensory cortex in adult owl monkeys after behaviorally-controlled tactile stimuli. J Neurophysiol 63:82-104.

Jimenez-Castellanos J, Graybiel AM (1989) Compartmental origins of striatal efferent projections in the cat. Neuroscience 32:297-321.

Jones EG, Coulter JD, Burton H, Porter R (1977) Cells of origin and terminal distribution of corticostriatal fibers arising in the sensorymotor cortex of monkeys. J Comp Neurol 173:53-80.

Jones EG, Coulter JD, Hendry SHC (1978) Intracortical connectivity of architectonic fields in the somatic sensory, motor and parietal cortex of monkeys. J Comp Ncurol 181:291-347.

Kassel J, Shambes GM, Welker W (1984) Fractured cutaneous projections to the granule cell layer of the posterior cerebellar hemisphere of the domestic cat. J Comp Neurol 225:458-468.

Koliatsos VE, Martin LJ, Hedreen J, Alexander GE, Hamada I, Price DL, Del_ong MR (1988) Organization of primate basal ganglia "motor circuit": 2. Putaminal projections to internal (GPi) and external (GPe) globus pallidus originate in distinct neuronal populations within the matrix compartment. Soc Neurosci Abstr 14:720.

Künzle H (1975) Bilateral projections from precentral motor cortex to the putamen and other parts of the basal ganglia. An autoradiographic study in Macaca fascicularis. Brain Res 88:195-209.

Künzle H (1978) Cortico-cortical efferents of primary motor and somatosensory regions of the cerebral cortex in Macaca fascicularis. Neuroscience 3:25-39.

Kwan HC, MacKay WA, Murphy JT, Wong YC (1978) Spatial organization of precentral cortex in awake primates. II. Motor outputs. J Neurophysiol 41:1120-1131.

Liles SL, Updyke BV (1985) Projection of the digit and wrist area of precentral gyrus to the putamen: relation between topography and physiological properties of neurons in the putamen. Brain Res 339: 245-255.

Malach R, Graybiel AM (1986) Mosaic architecture of the somatic sensory-recipient sector of the cat's striatum. J Neurosci 6:3436-3458.

McGuire PK, Bates JF, Goldman-Rakic PS (1991) Interhemispheric integration: II. Symmetry and convergence of the corticostriatal projections of the left and the right principal sulcus (PS) and the left and the right supplementary motor area (SMA) of the rhesus monkey. Cereb Cortex 1:408-417.

Mesulam M-M (1978) Tetramethyl benzidine for horseradish peroxidase neurohistochemistry: a non-carcinogenic blue reaction product with superior sensitivity for visualizing neural afferents and efferents. J Histochem Cytochem 26:106-117

Mink JW, Thach WT (1991) Basal ganglia motor control. I. Nonexclusive relation of pallidal discharge to five movement modes. J Neurophysiol 65:273-300.

Mori A, Waters RS, Asanuma H (1989) Physiological properties and patterns of projection in the cortico-cortical connections from the second somatosensory cortex to the motor cortex, area 4 gamma, in the cat. Brain Res 504:206-210.

Nelson ME, Bower JM (1990) Brain maps and parallel computers. Trends Neurosci 13:403-408.

Parthasarathy HB, Schall JD, Graybiel AM (1992) Distributed but convergent ordering of corticostriatal projections: analysis of the frontal eye field and the supplementary eye field in the macaque monkey. J Neurosci 12:4468-4488.

Percheron G, Filion M (1990) Parallel processing in the basal ganglia: up to a point. Trends Neurosci 14:55-56.

Schneider JS, Lidsky TI (1981) Processing of somatosensory information in the striatum of behaving cats. J Neurophysiol 45:841-851.

Selemon LD, Goldman-Rakic PS (1985) Longitudinal topography and interdigitation of corticostriatal projections in the rhesus monkey. $\mathrm{J}$ Neurosci 5:776-794.

Selemon LD, Goldman-Rakic PS (1990) Topographical intermingling of striatonigral and striatopallidal neurons in the rhesus monkey. $J$ Comp Neurol 297:359-376.

Sessle BJ, Wiesendanger M (1982) Structural and functional definition of the motor cortex in the monkey (Macaca fascicularis). J Physiol (Lond) 323:245-265.

Strick PL, Preston JB (1978a) Multiple representations in the primate motor cortex. Brain Res 154:366-370.

Strick PL, Preston JB (1978b) Sorting of somatosensory afferent information in primate motor cortex. Brain Res 156:364-368.

Tanji J, Wise SP (1981) Submodality distribution in sensorimotor cortex of the unanesthetized monkey. J Neurophysiol 45:467-481.

Tanji J, Okano K, Sato KC (1988) Neuronal activity in cortical motor areas related to ipsilateral, contralateral, and bilateral digit movements of the monkey. J Neurophysiol 60:325-343.

West MO, Carelli RM, Pomerantz M, Cohen SM, Gardner JP, Chapin JK, Woodward DJ (1990) A region in the dorsolateral striatum of the rat exhibiting single-unit correlations with specific locomotor limb movements. J Ncurophysiol 64:1233-1246.

Yeterian EH, Pandya DN (1991) Topography and laminar origin of corticocaudate projections in rhesus monkeys. Soc Neurosci Abstr $17: 454$.

Yeterian EH, Van Hoesen GW (1978) Cortico-striate projections in the rhesus monkey: the organization of certain cortico-caudate connections. Brain Res 139:43-63.

Yumiya H, Ghez C (1984) Specialized subregions in the cat motor cortex: anatomical demonstration of differential projections to rostral and caudal sectors. Exp Brain Res 53:259-276. 